Acta geotechnica manuscript No.

(will be inserted by the editor)

\title{
1 Non-isothermal soil-structure interface model based on critical state theory
}

\author{
Soheib Maghsoodi · Olivier Cuisinier • Farimah \\ Masrouri
}

6 Received: date / Accepted: date

\begin{abstract}
In energy geostructures, the soil-structure interface is subjected to thermo-mechanical loads. In this study, a non-isothermal soil-structure interface model based on critical state theory is developed from a granular soil-structure interface constitutive model under isothermal conditions. The model is capable of capturing the effect of temperature on sand/clay-structure interfaces under constant normal load and constant normal stiffness conditions. First, the developed model was verified for sand-structure interface in isothermal conditions. Then, it was calibrated for clay-structure interface under non-isothermal conditions. On one hand, a well-defined peak shear stress for the clay-structure interface and, on the other hand, the effect of temperature on the void ratio of the clay-structure interface were captured and reproduced by the model. The importance of interface thickness determination and some differences between the interface thicknesses of clay-structure and sand-structure interfaces are discussed in detail. The additional parameters have physical meanings and can be determined from laboratory tests. The modeling predictions are in good agreement with experimental results, and the main trends are properly reproduced.
\end{abstract}

Keywords energy geostructures $\cdot$ non-isothermal model $\cdot$ constant normal stiffness $(\mathrm{CNS}) \cdot$ soil-structure interface $\cdot$ temperature $\cdot$ critical state theory.

\section{Introduction}

The increasing demand for energy in recent years has lead to utilization of new technologies to exploit renewable energies. Among these developed techniques, thermally active energy geostructures and thermal energy storage systems can be mentioned (Brandl (2006), Adam and Markiewicz (2009), De Moel et al. (2010), Lahoori et al. (2020), Loveridge et al. (2020)). Conventional geostructures, such as piles and diaphragm walls, are converted to energy geostructures by attaching heat exchanger tubes to their reinforcement cages. Thermally active energy geostructures make heat exchange with the surrounding soil

Université de Lorraine, CNRS, LEMTA, Nancy, France

École supérieure d'ingénieurs des travaux de la construction, Metz, France

2 Rue du Doyen Marcel Roubault 54518 Vandœuvre-les-Nancy Cedex.

E-mail: soheib.maghsoodi@univ-lorraine.fr

Université de Lorraine, CNRS, LEMTA, Nancy, France

2 Rue du Doyen Marcel Roubault 54518 Vandœuvre-les-Nancy Cedex.

E-mail: olivier.cuisinier@univ-lorraine.fr

Université de Lorraine, CNRS, LEMTA, Nancy, France

2 Rue du Doyen Marcel Roubault 54518 Vandœuvre-les-Nancy Cedex.

E-mail: farimah.masrouri@univ-lorraine.fr 
possible by circulating a heat-carrying fluid in the exchanger loops. The thermo-mechanical solicitations, impact different parts of the system such as concrete body, soil-structure interface and surrounding soil. The soil-structure interface zone consists of a thin layer of soil adjacent to the structure in which normal and tangential stresses are acting on it. In energy geostructures, the interface zone will be exposed to thermo-mechanical loads. Several studies have shown a significant change in mobilized shaft friction with temperature variations in full scale energy foundations at soil-structure interface zone (Laloui et al. (2006), Bourne-Webb et al. (2009), Murphy et al. (2015), Faizal et al. (2018)). Therefore, the design and maintenance of energy geostructures requires additional precautions to take into account the effect of temperature variations on mechanical behavior of soil-structure interface. Due to the lack of interface thermo-mechanical constitutive models, it is noteworthy to propose a constitutive model for sandy and clayey interfaces in non-isothermal conditions.

There are several constitutive models in the literature proposed for thermo-mechanical behavior of soils (Hueckel and Borsetto (1990); Graham et al. (2001); Hueckel et al. (2009); Laloui and François (2009); Tang and Cui (2009); Hamidi and Khazaei (2010); Mašín and Khalili (2012); Yao and Zhou (2013)) but less attention has been paid to thermo-mechanical interface models. Moreover, most of the interface constitutive models proposed in the literature were developed for granular interfaces in isothermal conditions (Shahrour and Rezaie (1997), Ghionna and Mortara (2002), Fakharian and Evgin (2000), De Gennaro and Frank (2002), Mortara et al. (2002), Liu et al. (2006), Lashkari (2013)). Suryatriyastuti et al. (2014) proposed a t-z cyclic function to take into account the effect of thermal cycles on soil-pile interactions for cohesionless soils. However, for fine grained soil-structure interfaces, based on the knowledge of authors very few studies can be found in the literature (Stutz and Mašín (2017)). Regarding thermo-mechanical constitutive models for interface, the first model was proposed by Stutz, Mašín, Wuttke and Prädel (2016) which is based on thermo-mechanical hypoplastic model from Mašín and Khalili (2011) and Mašín and Khalili (2012). Concerning elasto-plastic models based on critical state concept which takes into account the effect of temperature (on void ratio) to the best knowledge of authors, no constitutive model can be found.

In this context, the aim of this study is to define an approach capable of capturing the major fundamental features of soil-structure interface regarding the effect of temperature. To this end, the paper will focus on two aspects:

- How can the effect of temperature on the mechanical properties of soil-structure interface be taken into account in the model?

- How can the model be capable to simulate both sand and clay-structure interface behavior under constant normal load (CNL) and constant normal stiffness (CNS) conditions?

This paper is divided into three sections. The first one gives a review of the main characteristics of the thermo-mechanical behavior of soil and the soil-structure interface that must be reproduced by the new model. The second part introduces the theoretical framework chosen for the interface behavior and the new formulation developed to capture the effect of temperature on the interface and finally, the model performance is examined.

\section{Thermo-mechanical behavior of soil and the soil-structure interface}

The key features of thermo-mechanical behavior of soil are first presented. Then, the experimental results concerning the effect of temperature on mechanical properties of soil-structure interface are discussed to highlight important features and aspects that should be taken into account by the interface constitutive model in non-isothermal conditions. 
72

\subsection{Features of thermo-mechanical behavior of soils}

Effect of temperature on shear characteristics of soils, remains a controversial subject and needs developed answers due to diverse results obtained by different studies (Campanella and Mitchell (1968); Houston and Lin (1987); Hueckel and Baldi (1990); Hueckel et al. (1998); Kuntiwattanakul et al. (1995); Cekerevac and Laloui (2004); Abuel-Naga et al. (2006); Yavari (2014); Liu et al. (2018)). These studies have indicated that, thermal and stress history, material intrinsic characteristics and drainage conditions (for heating and shearing) are the most important factors influencing shear characteristics of soils at non-isothermal conditions.

Hueckel et al. (1998) showed in high OCR clays, the soil during shear at higher temperatures reaches the yield limit at lower shear stresses and under drained heating the shear strength tends to reduce. The authors have explained this observation by ductile behavior of the soil upon heating. On the other hand Abuel-Naga et al. (2007) have found an increase in shear strength for overconsolidated clay at higher temperatures while Cekerevac and Laloui (2004) have reported that shear strength for highly overconsolidated kaolin at higher temperature remains unchanged. Generally in overconsolidated clays, temperature increase induces a reversible thermal expansion which consequently affects the shearing behavior. This temperature increase, decreases the preconsolidation pressure and consequently elastic domain shrinks.

Kuntiwattanakul et al. (1995) performed consolidated undrained triaxial tests on clays with drained heating. The authors have observed undrained shear strength increased from 20 to $90{ }^{\circ} \mathrm{C}$ while Murayama (1969); Sherif and Burrous (1969) and Laguros (1969) claimed that undrained heating caused a reduction in undrained shear strength of different clayey samples during unconfined compression tests.

For normally consolidated clays, the deformation upon heating is contractive and irreversible, and thus, the shear strength of the soil increases with temperature. In this state, the soil becomes denser with temperature increase under constant isotropic stress. Cekerevac and Laloui (2004) and Abuel-Naga et al. (2007) have found an increase of shear strength with drained heating on kaolin clay and soft Bangkok clay respectively. In NC clays, the contraction upon heating mainly is the void ratio decrease, which is commonly called the thermal overconsolidation effect. As can be observed controversial results are obtained concerning the shear strength of clays at different temperatures, because of this confusing results it can be concluded that the shear characteristics of clay at higher temperature is material specific (Hueckel et al. (2009)).

\subsection{Features of the thermo-mechanical behavior of the soil-structure interface}

Several experimental studies have been performed on the effect of temperature on mechanical behavior of soil-structure interface in direct shear tests regarding the monotonic behavior (Di Donna et al. (2015); Yavari et al. (2016); Li et al. (2018); Maghsoodi (2020); Maghsoodi et al. (2019); Maghsoodi et al. (2020b); Yazdani et al. (2019)); cyclic response (Maghsoodi et al. (2020a), Maghsoodi et al. (2020c)) and centrifuge models (McCartney and Rosenberg (2011)). One of the first studies was conducted by Di Donna et al. (2015) in which, quartz sand-concrete interface at 20 and $60{ }^{\circ} \mathrm{C}$ and illite clay-concrete interface at 20 and $50{ }^{\circ} \mathrm{C}$ were tested. The dense sand interface showed a thermally elastic behavior. On the contrary the illite clay interface exhibited an increase in shear strength upon heating. The shear strength increase was translated by an augmentation in adhesion of the interface from 7 to $20 \mathrm{kPa}$ with heating from 20 to 50 ${ }^{\circ} \mathrm{C}$. Yavari et al. (2016) conducted interface tests between concrete structure and Fontainebleau sand and kaolin clay at 5, 20 and $40{ }^{\circ} \mathrm{C}$. They observed that the friction angle and adhesion showed a negligible variation to heating/cooling. They explained, this observation was due to the thermo-mechanical path applied in experiments. All of the samples were consolidated up to $100 \mathrm{kPa}$ and heated up to $40{ }^{\circ} \mathrm{C}$ before imposing the desired temperature or normal stress. Yazdani et al. 2019 have performed a series of direct shear tests using a temperature controlled direct shear apparatus to evaluate the effect of heating/cooling 
cycles on kaolin clay-concrete interface strength. The temperature cycles were between 24 and $34{ }^{\circ} \mathrm{C}$ to simulate the real thermal conditions of an energy pile. They found that due to temperature increase, the peak friction angle of $\mathrm{NC}$ clay-concrete interface increased, while the interface adhesion decreased. Thermally induced hardening of $\mathrm{NC}$ clay-concrete interface was found to be minor at a low normal stress $(150 \mathrm{kPa})$, while it was significant at higher normal stresses $(225$ and $300 \mathrm{kPa})$.

Among these studies, the experimental results of Maghsoodi et al. (2020b) are presented in the following. Fig. 1 shows the constant normal load (CNL) and constant normal stiffness (CNS) test results of a normally consolidated kaolin clay-structure interface for two different normal stresses, 100 and 300 $\mathrm{kPa}$, at 22 and $60{ }^{\circ} \mathrm{C}$. The shear stress-displacement behavior of the normally consolidated clay-structure interface exhibited a clear peak under CNL and CNS conditions. For both CNL and CNS tests, the peak shear stress of the kaolin clay-structure interface increased with heating from 22 to $60{ }^{\circ} \mathrm{C}$. However, at the critical state (large displacements), the effect of temperature was negligible (Fig. 1(a) and (b)). The shear stress increase upon heating in CNS tests was less than CNL results. The thermal overconsolidation effect during heating reduced the contraction of the interface during shear. Fig. 1(c) and (d) show the volumetric behavior in both CNL and CNS tests. Due to the increase in stiffness, the volumetric contraction in the CNS tests was less than that in the CNL tests. Fig. 1(e) and (f) show the evolution of the normal stress during shear. For the CNL tests, the normal stress remained unchanged. However, in the CNS tests, to keep the ratio $d \sigma / d U=K$ constant, the normal stress decreased during shearing.

In the above-mentioned studies, the authors found that the shear strength of the clay-structure interface increases with temperature. However, the shear strength of the sand-structure interface remains unchanged. They concluded that the shear stress increase in the clay-structure interface could be due to thermally induced overconsolidation of normally consolidated clay. To support this statement, data from Maghsoodi et al. (2020b) are provided. Fig. 2(a) shows the thermal vertical strain for a kaolin claystructure interface under $300 \mathrm{kPa}$ during the heating phase and after consolidation. Heating from 22 to 60 ${ }^{\circ} \mathrm{C}$ caused a thermal vertical strain of $0.85 \%$ for the clay-structure interface. Fig. 2 (b) shows the evolution of the void ratio during shear for clay-structure interface tests performed under $100 \mathrm{kPa}$ at 22 and $60{ }^{\circ} \mathrm{C}$. The initial void ratio for the heated sample was reduced, but at the critical state, both void ratios were superposed, which can explain the identical shear behavior of the interface at large displacements (Fig. $1(\mathrm{a})$ and (b)).

\subsection{Summary}

The model should be able to capture the effect of temperature on the soil-structure interface and should require a limited number of parameters to capture the maximum features of the soil-structure interface. Despite the dependency of other shearing factors of interface on temperature this study focuses on the effect of temperature on void ratio. Important features that should be captured by the model are as follows:

- The void ratio reduction upon heating for normally consolidated clay-structure interface.

- The stress-strain behavior of normally consolidated clay-structure interfaces under CNL and CNS conditions.

- The volumetric behavior of clay-structure interfaces at different temperatures during shear under both CNL and CNS conditions.

- The evolution of the normal stress during shear corresponding to CNL and CNS results. 


\section{Development of a constitutive model for soil-structure interface}

\subsection{Isothermal soil-structure interface constitutive model}

The aim of this work is to develop an interface model capable of reproducing several features of the soil-structure interface mechanical behavior in non-isothermal conditions. To do so, a model principally based on void ratio evolution can be used to take into account the effect of temperature on the initial void ratio of the interface. Generally, implementing additional variables (e.g., temperature) in a constitutive model requires the incorporation of more parameters. However, increasing the number of parameters causes more complexity. Therefore, models with a minimum number of parameters that have physical meaning obtained from classical laboratory tests on one hand and are able to capture the maximum number of features on the other hand are required. The model should be flexible for both CNL and CNS conditions and should be feasible and adoptable for implementation. Several constitutive models have been proposed for soil-structure interface behavior (Desai et al. (1985), Shahrour and Rezaie (1997), Ghionna and Mortara (2002), Fakharian and Evgin (2000), De Gennaro and Frank (2002), Mortara et al. (2002), Boulon et al. (2003), Liu et al. (2006), D’Aguiar et al. (2011), Lashkari (2013), Saberi et al. (2016), Saberi et al. (2017), Stutz, Mašín and Wuttke (2016)), and some of them are based on critical state theory (Liu et al. (2006), Lashkari (2017)).

Among the pre-existing models for soil-structure interface, available in the literature, the critical state interface model proposed by Lashkari (2017) is based on the void ratio evolution during shear. The model is relatively straightforward in its application and has parameters that have physical meanings. Therefore, this model fits well within the mentioned requirements and is thus selected. The model is adopted as the base for developing a new constitutive model for non-isothermal conditions.

\subsubsection{Modeling formulation}

The concept of the critical state is based on the theory that at large shear deformations, soil continues to shear without any changes in volumetric and stress conditions. The void ratio at this large shear deformation is the critical state void ratio $\left(e_{c s}\right)$. The critical state void ratio tends to decrease with increasing the normal stress. Therefore, the shear and volumetric behavior of the soil/soil-structure interface depends on the difference between current and critical state. This difference is defined as the state parameter (Liu et al. (2006)).

The constitutive formulations used in Lashkari (2017) is given in table 1. Lashkari (2017) proposed the following function for the evolution of the interface void ratio with shear strain:

$$
e=e\left(e_{i n}, e_{c s}, \epsilon\right)=e_{c s}[1-\exp (-\xi \epsilon)]+e_{i n} \exp (-\xi \epsilon)-\frac{k_{1}}{1+K / k_{2}}(\epsilon) \exp (-\xi \epsilon),
$$

The current void ratio $(e)$ is a function of initial $\left(e_{i n}\right)$, critical state void ratio $\left(e_{c s}\right)$ and shear strain $(\epsilon)$. The deformation $(\epsilon)$ is defined as the shear displacement divided by the interface thickness $(\Delta w / t)$. The parameter $\xi$ controls the rate of void ratio evolution with shear strain $(\epsilon) . K$ is the normal stiffness acting on the interface. The parameters $k_{1}$ and $k_{2}$ are fitting parameters. Fig. 3(a) shows Eq. 1 for different initial void ratios (0.7-1.2). For dense samples, $e_{i n}<e_{c s}$, and for loose samples, $e_{i n}>e_{c s}$. The dense sample with $e_{i n}=0.70$ exhibits an initial contraction upon shearing followed by dilation after phase transformation. In the sample with $e_{i n}=0.8$, a larger initial contraction phase is obtained, followed by dilation. Finally, the soils with $e_{i n}=0.9,1.0,1.1$, and 1.2 exhibit contraction until the shearing ceases. As can be observed, independent of initial void ratio, the curves converge towards a single state which is the critical state void ratio. The capability of Eq. 1 to properly describe the void ratio evolution has been checked by using data from Pra-ai and Boulon (2017) for Fontainebleau sand-steel interface shear tests (Fig. 3(b)). For loose and dense samples, the relative density (ID) was 30\% and 90\%, respectively. The initial void ratios of loose and dense samples were $e_{i n}=0.760$ and 0.577 , respectively. As observed 
for Eq. 1, the loose sample contracted until the end of shearing. In contrast, the dense sample exhibited a slight contraction followed by a dilation. Both loose and dense sand void ratios reached asymptotic values at larger shear displacements. The evolution of the void ratio was experimentally observed and thus the equation was validated for sand-structure interface tests.

Another important aspect of the reference interface model is the ability to reproduce the interface behavior under constant normal stiffness (CNS) conditions. The normal stress variation in CNS conditions depends on the volumetric behavior of the interface.

In CNS conditions, the free contractive or dilative volumetric evolution of the interface upon shearing is prevented by the surrounding soil stiffness. The dilative response is counteracted by an increase of normal stress. On the contrary the contractive response is accompanied by a reduction of normal stress. Therefore, interface and surrounding soil interactions can be expressed as:

$$
\delta \sigma_{n}^{\prime}=-K . \delta U
$$

where $\delta \sigma_{n}(\mathrm{kPa})$ is the normal stress difference on the interface, $K(\mathrm{kPa} / \mathrm{mm})$ is the surrounding soil stiffness and $\delta U(\mathrm{~mm})$ is the difference in normal displacement of the interface. Considering the thickness of the interface $(t)$, the void ratio evolution of the interface upon the normal stress changes can be obtained by the following equation:

$$
\delta \sigma_{n}^{\prime}=-K \delta U=\frac{-K t \delta e}{1+e},
$$

where $t$ is the interface thickness. Several studies have proposed that in a granular interface, the thickness of the interface is approximately 5 to 10 times the $D_{50}(\mathrm{~mm})$ of the soil (Boulon and Foray (1986), Fakharian and Evgin (1997), DeJong et al. (2003)). Pra-ai and Boulon (2017) has reported that the soil-structure interface zone cannot be clearly distinguished from the surrounding soil. The shearing behavior of the interface is different from that of the surrounding soil. Boulon (1989) proposed a new interpretation of the interface. They suggested that in interface direct shear tests, the sample consists of two parts: the active part, which is in contact with the structural element, and the passive part, which is mainly subjected to normal stress. The active part is influenced by the interface thickness.

As it was discussed the model is based on critical state concept which is mainly governed by the critical state void ratio $\left(e_{c s}\right)$. Therefore, most of the interface responses concerning the void ratio evolution, shear stress variations and normal stress changes are influenced by the critical state void ratio $\left(e_{c s}\right)$. This parameter can be determined using the critical state line (CSL) in the $e$-ln $\sigma$ plane as follows:

$$
e_{c s}=\Gamma-\lambda \ln \left(\sigma_{n}^{\prime} / p_{\text {ref }}\right),
$$

where $\Gamma$ and $\lambda$ are interface parameters, and $p_{\text {ref }}=100 \mathrm{kPa}$ is reference pressure.

The difference between initial and critical void ratio is defined as the state parameter (Been and Jefferies (1985), DeJong et al. (2003), Liu et al. (2006)). The interface state parameter $\psi$ can be defined as:

$$
\psi=e-e_{c s}
$$

The dense interfaces have some particularities: (i) reveal a clear peak in shear stress-displacement response; (ii) contract at the beginning, afterwards phase transformation occurs then followed by a dilation. The dilation is caused by the void ratio increase from the initial value to the critical one $(\psi<0)$. For the loose interfaces: (i) no peak is observed in shear stress-displacement response; (ii) contracts throughout the shearing and the void ratio is descending $(\psi>0)$.

To predict the shear stress of the interface Lashkari (2017) proposed the following equation:

$$
\tau=\frac{\epsilon}{\frac{1}{\mu}+\frac{\epsilon}{M \sigma_{n}[1+N\langle-\psi\rangle]}},
$$


At critical state in $\tau-\sigma_{n}$ plane, the slope of the critical state line is equal to $M . \mathrm{N}$ is an interface parameter that impacts the peak shear stress of the interface, and $\mu$ is the interface elastic shear modulus.

\subsection{Extension of the constitutive model to non-isothermal conditions}

For normally consolidated clays, heating induces a contraction of the soil. The model should be able to evaluate the initial void ratio of the clay after heating. Therefore, a relationship to account for the reduction of the void ratio upon heating was proposed and implemented in the model (Eq. 1). The slope of the void ratio reduction with temperature $(\alpha)$ has been evaluated for normally consolidated claystructure interfaces (Fig. 4). The following equation can be used to determine the initial void ratio at any temperature:

$$
e_{i n(T)}=e_{i n}-\alpha \cdot\left(T-T_{0}\right)
$$

where $e_{i n(T)}$ is the initial void ratio at temperature $T$. The parameter $\alpha$ is a material-dependent parameter that is influenced by the physical, thermal and mineralogical characteristics of the soil. Using this parameter, when the initial void ratio is known, by implementing Eq. 10 in Eq. 1, the evolution of the void ratio during shear at any temperature is:

$$
e=e_{c s}[1-\exp (-\xi W)]+\left(e_{i n}-\alpha . \Delta T\right) \exp (-\xi W)-\frac{k_{1}}{1+K / k_{2}} W \exp (-\xi W) .
$$

The reference model can reproduce the behavior of loose interfaces as well. For loose interfaces, the volumetric behavior is contractive, and no peak shear stress is expected. For the clay-structure interface tests at different temperatures, several authors reported a clear peak in the shear stress-displacement curve despite the normally consolidated states of the clay (Yavari et al. (2016); Maghsoodi et al. (2020b) and Yazdani et al. (2019)). The developed model should have the capability to reproduce this feature. Therefore, the shear stress-strain equation was modified as follows:

$$
\tau=\frac{W}{\frac{1}{k_{t}}+\frac{W}{\left(\left(\tan \delta+\frac{c}{\sigma_{0}^{\prime}}\right)\left(\sigma_{n}^{\beta}\right)\right)[1+N\langle-\psi\rangle] \cdot \exp \left(-(W / N)^{k_{2}}\right) \xi+\beta}} .
$$

In this equation, due to the strong dependence of the clay-structure interface behavior on the adhesion of the interface (cohesion between the soil and structure), instead of using $\mathrm{M}$ as a frictional parameter, the adhesion (cohesion between the soil and structure) (C) and friction angle $(\delta)$ have been introduced into the model. In the model of Lashkari (2017), the shear stress-strain equation, the parameters and their values have been used for the sand-structure interface. For this type of interface, the ratio of $\tau / \sigma_{n}$ is relatively high compared to the clay-structure interface response. Therefore, an additional parameter named $\beta$ has been introduced to control the effect of normal stress. The additional term on the right-hand side of the equation allows a clear peak to appear in the shear stress-strain curve despite the normally consolidated state of the clay-structure interface.

The initial slope of the elastic part can be presented as follows:

$$
k t=k t_{0}\left(\frac{\sigma_{n}^{\prime}}{p_{\text {ref }}}\right)^{n}
$$

where $k t_{0}(\mathrm{kPa} / \mathrm{mm})$ is the initial slope of the elastic part of the stress-displacement curve, $\sigma_{n}^{\prime}(\mathrm{kPa})$ is the current normal stress, $p_{\text {ref }}$ is a reference pressure $(100 \mathrm{kPa})$ and $n(-)$ is the nonlinear exponent. 


\subsubsection{Parameter definitions}

The non-isothermal model has 12 parameters (Table 2). In the $\tau$ vs. $W$ plane, $k_{t 0}$ is the initial slope of the elastic part of the stress-displacement curve (Fig. 5(a)). In the Mohr-Coulomb plane, $C$ and $\delta$ are the intercept and slope of the failure line (Fig. 5(b)). $\Gamma$ and $\lambda$ are the intercept and slope of the CSL in the $e$ vs. $\ln \left(\sigma_{n}^{\prime} / P_{r e f}\right)$ plane, respectively (Fig. $5(\mathrm{c})$ ). In contractive regime (loose sand, normally consolidated clay), the volumetric curve decreases towards the critical state. The point at which the volumetric curve reaches the critical state phase corresponds to $W_{1}$. This is then used to determine the $\xi$ parameter. In dilative regime (dense sand, overconsolidated clay), the volumetric curve exhibits a phase transformation and an inflection point (Fig. 5(d)). The phase transformation point is the first derivative of $d e / d W=0$, and the inflection point is the second derivative of $d^{2} e / d W^{2}=0$. The shear strains corresponding to these points, $W_{2}$ and $W_{3}$, play a major role in determining the $\xi$ parameter. $\xi$ can be evaluated for contractive and dilative interfaces using the following equations, respectively:

$$
\begin{gathered}
\xi=\frac{1}{W_{1}}, \\
\xi=\frac{1}{W_{2}-W_{3}} .
\end{gathered}
$$

$\xi$ controls the rate of the void ratio evolution during shearing. $\mathrm{N}$ impacts the peak shear stress and the strain-softening after it. It can be obtained by calibration against experimental results. In dense regimes the initial contraction amplitude is influenced by $k_{1}\left(\mathrm{~mm}^{-1}\right) . k_{2}(\mathrm{kPa} / \mathrm{mm})$ modifies the form of the shear stress curve. By model calibration against experimental data and trial and error iterations, both $k_{1}$ and $k_{2}$ can be determined. In the lack of experimental data for sand-structure interface tests, $0.6 \mathrm{~K} \leq$ $k_{1} \leq 0.8 \mathrm{~K}$ (from CNL to CNS) and $0.1 \leq k_{2} \leq 0.6$ (from CNL to CNS) are appropriate estimations.

\subsubsection{Parametric study}

A parametric study was performed to evaluate the relative weight of each parameter (Fig. 6). The parametric study conditions include a normal stress of $300 \mathrm{kPa}, \Gamma=0.967$ and an initial void ratio of $e_{i n}=0.85$ at $T=22^{\circ} \mathrm{C}$, which correspond to a normally consolidated kaolin clay-structure interface. Increasing $k_{t}$ from 170 to $680 \mathrm{kPa}$ increases the elastic slope of the shear stress-displacement curve, the peak shear stress and, very slightly, the residual shear stress (Fig. 6(a)). Increasing $N$ from 1.85 to 4.85 changes the shape of the stress-displacement curve. With increasing $N$, the peak shear stress increases and simultaneously moves towards larger shear displacements. The impact of $\Gamma$ and $\lambda$ variations on the model performance are presented in Fig. 6(c) and (d). An augmentation in $\Gamma$ for normally consolidated interfaces, decreases the distance between initial and critical void ratio $\left(\psi=e_{i n}-e_{c s}\right)$ and therefore the contraction reduces (Fig. 6(c)). However, in contrast, an increase in $\lambda$ amplifies the contraction during shear. Increasing $\xi$ from 0.5 to 0.9 increases the rate of volumetric contraction towards the critical state condition (Fig. 6(e)). The model response under variation of $\xi$ in Fig. 6(f) indicates that an increase in $\xi$ increases the peak shear strength without influencing the residual strength. Variation of $k_{2}$ from 1.9 to 3.9 increases the peak shear stress, and strain softening is exhibited after the peak of the shear stressdisplacement curve (Fig. 6(g)). An increase in $\beta$ raises the shear stress-displacement curves obtained under the same normal stress. For example, under $\sigma_{n}=300 \mathrm{kPa}, \Gamma=0.967$ and an initial void ratio of $e_{i n}=0.85$, an increase in $\beta$ from 0.85 to 0.98 increases both the peak and residual shear strengths of the interface. 


\section{Model performance}

In the following section, the model performance with respect to sand/clay-structure interface tests under CNL and CNS conditions at different temperatures is examined using experimental data from the literature. The characteristics of the corresponding soils are provided in Table 3 and Table 4.

\subsection{Sand-structure interface in isothermal conditions}

Maghsoodi et al. (2020b) performed Fontainebleau sand-steel interface direct shear tests at different temperatures $\left(22\right.$ and $\left.60{ }^{\circ} C\right)$. The sand was prepared with a relative density of $90 \%\left(\mathrm{e}_{i n}=0.557\right)$. The model performance was first tested against the sand-structure interface experimental results with the knowledge that the effect of temperature on the mechanical properties of sandy interfaces was negligible. The shear stress-displacement curve of the sand-structure interface exhibited a clear peak due to the dense state of the sand. Using the values in Table 2, the modeling results are in good compliance with the experimental results of CNL sand-structure interface tests (Fig. 7). The friction angle was equal to $40^{\circ}$, the value of $\Gamma$ was found to be 0.835 , and a $\lambda$ of 0.040 was obtained. Based on experimental observations, $W_{1}=0.37$ and $W_{2}=1$, and therefore, $\xi$ was found to be 1.58. Due to trial and error, $N$ was found to be $2.2, K$ was $0, k_{1}$ was found to be 0.5 , and $k_{2}$ was 0.5 . The thickness of the interface, $t$, was $1.15 \mathrm{~mm}(5$ $\times D_{50}(0.23 \mathrm{~mm})$ ), and the $\beta$ parameter was 0.94 for this kind of soil. To find $N$, it is sufficient to find the displacements corresponding to the peak shear stress, and the strain-softening phase (near the critical state part). Then, the difference between these values corresponds to N.

Fig. 8 shows the modeling results against CNS Fontainebleau sand-steel interface tests obtained by Maghsoodi et al. (2020b). In these tests, the initial normal stress was $100 \mathrm{kPa}$ and the normal stiffness was 1000 and $5000 \mathrm{kPa} / \mathrm{mm}$. The model parameters were derived from CNL results with some modifications. The value of $\Gamma$ is different in CNS tests due to the effect of normal stiffness. Increasing stiffness will decrease the dilatancy and consequently the critical void ratio decreases compare to CNL case. The $\Gamma$ was found to be 0.67 under $\mathrm{K}=5000 \mathrm{kPa} / \mathrm{mm}$. The other different parameter is $k_{1}$ which is a fitting parameters. $k_{1}$ was found to be 3000 . Fig. 9 shows modeling results against the second series of the CNS sand-structure interface tests with a constant normal stiffness $(1000 \mathrm{kPa} / \mathrm{mm})$ and different initial normal stresses $(100,200$ and $300 \mathrm{kPa})$.

Fig. 10 shows CNL and CNS quartz sand-concrete structure interface tests by Di Donna et al. (2015). In CNL tests, three normal stress of 50, 100 and $150 \mathrm{kPa}$ were applied. For CNS tests, two tests with initial normal stress of 50 and $100 \mathrm{kPa}$ under $\mathrm{K}=1000 \mathrm{kPa} / \mathrm{mm}$ were conducted. Using the values in Table 2 , the modeling results are in reasonable agreement with the experimental results for CNS tests.

De Gennaro and Frank (2002) performed interface direct shear tests on a loose Fontainebleau sandrough steel plate. The physical characteristics of the sand are presented in Table 3. Loose sand samples were reconstituted by pouring dry sand into a square shear box of size $60 \mathrm{~mm}$ x $60 \mathrm{~mm}$. Following this procedure, the relative density ID equal to $0.46\left(e_{i n}=0.753\right)$ was obtained. Three different normal stresses $(25,50$ and $100 \mathrm{kPa})$ were applied. For tests at 25 and $50 \mathrm{kPa}$, the interface dilated. However, for the test at $100 \mathrm{kPa}$, the volumetric behavior was contractive. Based on the results reported by De Gennaro and Frank (2002), the friction angle was $40^{\circ}$, and the cohesion was 0 . The $\Gamma$ was equal to 0.815 and $\lambda=$ 0.040 was found. Similarly to the Fontainebleau results reported by Maghsoodi et al. (2020b), $W_{1}=0.37$ and $W_{2}=1$ were obtained therefore, $\xi$ was 1.58 . Similar, $N$ was found to be $2.2, K$ was $0, k_{1}$ was equal to 0.21 and $k_{2}$ was 0.11 . The thickness of the interface, $t$, was $1.15 \mathrm{~mm}$, and the $\beta$ parameter was 0.91 . Using the values in Table 2, the modeling results satisfactorily duplicated the experimental results for CNL tests (Fig. 11).

Fakharian and Evgin (2000) performed constant normal load and constant normal stiffness simple shear interface tests between samples of silica sand and steel plates with different roughnesses using a Cyclic 3-Dimensional Simple Shear Interface apparatus. The physical characteristics of the silica sand are 
summarized in Table 3 . The sand was prepared with a relative density of 0.88 . The tests were performed with different stiffness values of $K=0,400$ and $800 \mathrm{kPa} / \mathrm{mm}$ for an initial normal stress of $100 \mathrm{kPa}$ (Fig. 12). Imposing the stiffness caused variation of the normal stress acting on the interface. The dilative response of dense interface upon shearing, was constrained by the stiffness and consequently caused an normal stress augmentation. The first test with $K=0(\mathrm{CNL})$ was used for model calibration, and the other results were predicted using this test. With $\mathrm{D}_{50}=0.6(\mathrm{~mm})$, the interface thickness was calculated to be $3(\mathrm{~mm})$. A friction angle of $40^{\circ}$ was used in the model. After model calibration for $\sigma_{n}=100 \mathrm{kPa}$, the parameters were used for model prediction of constant normal stiffness tests $(K=400,800 \mathrm{kPa} / \mathrm{mm})$. The results of the simulations are presented in Fig. 12. The model predictions showed a reasonable replication of experimental results.

\subsection{Clay-structure interface in non-isothermal conditions}

Fig. 13 shows the modeling simulations against experimental results from Di Donna et al. (2015) for illite clay-concrete interface. The peak shear stress for illite clay-concrete interfaces is as not clear as in the case of (Maghsoodi et al. (2020b)). Therefore, the shape of the stress-displacement curves that should be reproduced by the model is different from that in other cases. As indicated in their study, the friction angle of the illite clay-concrete was $25^{\circ}, \Gamma$ was $0.870, \lambda$ was 0.140 , and $\xi$ was found to be 0.8 , with $N=4$, $k_{1}=0.003, k_{2}=0.7, C=7$ and $\beta=0.96$. Therefore, the model predictions using the values in Table 2 are presented in Fig. 13. Calibration tests were performed for $\sigma_{n}=50 \mathrm{kPa}$, and predictions were carried out for other stresses.

Yazdani et al. (2019) performed kaolin clay-concrete interface tests at different temperatures (24 and $34{ }^{\circ} \mathrm{C}$ ). The normally consolidated clay-concrete interfaces were tested under 3 different normal stresses $(150,225$ and $300 \mathrm{kPa})$. A temperature increase increased the peak and residual shear strengths of the interface. Under higher normal stresses, the effect of temperature on the shear stress of the interface was more pronounced. Using the values in Table 2, the model capacity to reproduce the interface behavior is presented in Fig. 14. The model results are in good agreement with the experimental data. Calibration of the model was performed for the tests at $150 \mathrm{kPa}$, and the prediction capability was examined for other stresses.

Maghsoodi et al. (2020b) performed kaolin clay-steel interface direct shear tests at different temperatures $\left(22\right.$ and $\left.60{ }^{\circ} \mathrm{C}\right)$. After the consolidation phase, CNL and CNS tests were performed. The kaolin clay was initially in a normally consolidated state. Subsequent heating induced a thermal overconsolidation associated with contraction of samples. During shearing, the heated samples showed a higher peak shear stress compared to the unheated samples. The model simulations and corresponding experimental data for CNL tests are shown in Fig. 15. A remarkable peak is discernible in the behavior of all samples and is captured in the simulations. It can be seen that the predicted results are satisfactory. For CNS tests, using the parameters in Table 2, the modeling results are in very good agreement with the experimental data (Fig. 16). For CNS tests, the difference between the peak shear stress at different temperatures is less than that for the CNL case due to the effect of stiffness (Fig. 16(a)). The volumetric behavior during shearing can be observed for both modeling and experimental results in Fig. 16(b) and Fig. 16(c) illustrates the modeling results for the normal stress evolution during shear at different temperatures versus the experimental results. The Mohr-Coulomb plane is shown in Fig. 16(d) and (e). Due to the effect of the stiffness on the critical void ratio $\left(e_{c s}\right), \Gamma=0.97$ is higher than for the CNL case because the volumetric contraction is reduced in CNS tests. As discussed for the interface thickness formulation (Eq. 3 ), regarding the effect of interface thickness on the volumetric behavior under CNS and CNL conditions, for clayey interfaces, the thicknesses of the clay-structure interfaces are approximately $3-4 \mathrm{~mm}$ in this study (based on values mentioned in literature). 


\section{Discussion and conclusion}

The main objective of this study was to develop an approach to model the impact of temperature on the behavior of soil-structure interfaces. The developed non-isothermal model is based on the critical state concept, and it is an extension of a constitutive model for granular soil-structure interfaces under isothermal conditions. The extended model is capable of reproducing the experimental results of sand/clay-structure interfaces at different temperatures under both constant normal load (CNL) and constant normal stiffness (CNS) conditions. The following remarks can be mentioned:

- The experimental evidence confirmed the thermal independence of mechanical behavior of sandstructure interface under CNL and CNS conditions (Di Donna et al. (2015); Yavari et al. (2016); Maghsoodi et al. (2020b)). The modeling performance with respect to different CNL and CNS results is satisfactory, and the main features of sand-structure behavior are reproduced. For CNL tests, the peak shear stress and dilatancy behavior of the sand-structure interface are reproduced by the model. For CNS tests, the model was capable of reproducing the shear stress-displacement response of the sandstructure without showing any clear peak. The normal stress variations have been modeled correctly, and the volumetric behavior has also been reproduced.

- The void ratio evolution of the normally consolidated (NC) clay-structure interface during shearing is contractive, similar to what can be observed in loose sand-structure interfaces. However, the shear stress-displacement response of NC clay-structure interface exhibits a well-defined peak. Several authors have confirmed this behavior, and they have explained that the combination of complex shearing modes (I, II and III) may be the reason for this observation (Tsubakihara and Kishida (1993), Lemos and Vaughan (2000)). The model was developed such that it could capture the peak shear stress of the clay interface.

- Several experimental investigations confirmed the shear strength dependence of clayey interfaces on thermal variations (Di Donna et al. (2015); Yavari et al. (2016); Maghsoodi et al. (2020b)). This dependence could be via different mechanisms. In this study thermal dependence of void ratio was considered. A new formulation was developed to account for the effect of temperature on void ratio of clay-structure interfaces. The consequent effect of the void ratio evolution appeared to be an increase in the peak shear stress-displacement response. The extended model formulation was flexible enough to capture these features.

- The other important aspect of the model was the difference between CNL and CNS soil-structure interface responses. Regarding sand-structure interface parameters, the thickness of interface $(t)$ was found to be approximately 5-10 times $D_{50}$, which was experimentally observed by several authors (DeJong et al. (2003), Sadrekarimi and Olson (2010), Martinez et al. (2015)). However, clay-structure interface thickness is difficult to be determined experimentally. Martinez and Stutz (2018) have shown that the thickness of interface in kaolin clay-rough steel structure interface tests can be 2-3 mm. Kuo and Bolton (2014) and Kuo et al. (2015) conducted interface direct shear tests on deep-ocean clays using a torsional direct shear device. Using particle image velocimetry techniques, they found the thickness of interface to be $2 \mathrm{~mm}$. In our extended non-isothermal model, the interface thickness could not be determined with the model therefore, values in the same range mentioned in literature for interface direct shear tests $(2-4 \mathrm{~mm})$, were selected for the clay-structure interface thickness $(t)$.

- Regarding the model parameters, they can be determined using a temperature-controlled direct shear device. The critical state parameters $(\Gamma$ and $\lambda)$ can be estimated from a consolidation test. The void ratio of the clay before and after heating is also straightforward to determine. The mechanical characteristics $(\delta$ and $C$ ) can be found by performing shear tests under different normal stresses using the direct shear device. These parameters have physical meanings, which makes it easier to find their influence on the modeling performance.

- The overconsolidated clay-structure interface behavior at different temperatures could not be reproduced by the model due to the lack of experimental results in the literature. Therefore, first, experimental tests on overconsolidated clay-structure interface behavior at different temperatures should be performed, 
and then, the results can be used for further development of the model. The void ratio evolution in overconsolidated clays is similar to that in dense sand-structure interfaces. Therefore, to introduce the effect of temperature on an overconsolidated clay-structure interface, formulation modification of the void ratio evolution should be implemented. Another important concern of the soil-structure interface behavior is the effect of roughness, which would require further extension of the model. The effect of roughness has not been explicitly implemented in the modeling formulation and the model calibration can differ when the roughness changes.

\section{References}

Abuel-Naga, H., Bergado, D., Ramana, G., Grino, L., Rujivipat, P. and Thet, Y. (2006). Experimental evaluation of engineering behavior of soft bangkok clay under elevated temperature, Journal of geotechnical and geoenvironmental engineering 132(7): 902-910.

Abuel-Naga, H. M., Bergado, D. T. and Lim, B. F. (2007). Effect of temperature on shear strength and yielding behavior of soft bangkok clay, Soils and Foundations 47(3): 423-436.

Adam, D. and Markiewicz, R. (2009). Energy from earth-coupled structures, foundations, tunnels and sewers, Géotechnique 59(3): 229-236.

Been, K. and Jefferies, M. G. (1985). A state parameter for sands, Géotechnique 35(2): 99-112.

Boulon, M. (1989). Basic features of soil structure interface behaviour, Computers and Geotechnics 7(1-2): 115-131.

Boulon, M. and Foray, P. (1986). Physical and numerical simulation of lateral shaft friction along offshore piles in sand, Proceedings of the 3rd International Conference on Numerical methods in Offshore piling, Nantes, France, pp. 127-147.

Boulon, M., Ghionna, V. N. and Mortara, G. (2003). A strain-hardening elastoplastic model for sandstructure interface under monotonic and cyclic loading, Mathematical and computer modelling 37(56): 623-630.

Bourne-Webb, P., Amatya, B., Soga, K., Amis, T., Davidson, C. and Payne, P. (2009). Energy pile test at lambeth college, london: geotechnical and thermodynamic aspects of pile response to heat cycles, Géotechnique 59(3): 237-248.

Brandl, H. (2006). Energy foundations and other thermo-active ground structures, Géotechnique 56(2): $81-122$.

Campanella, R. G. and Mitchell, J. K. (1968). Influence of temperature variations on soil behavior, Journal of Soil Mechanics and Foundations Division 94(SM3): 709-734.

Cekerevac, C. and Laloui, L. (2004). Experimental study of thermal effects on the mechanical behaviour of a clay, International journal for numerical and analytical methods in geomechanics 28(3): 209-228.

D'Aguiar, S. C., Modaressi-Farahmand-Razavi, A., Dos Santos, J. A. and Lopez-Caballero, F. (2011). Elastoplastic constitutive modelling of soil-structure interfaces under monotonic and cyclic loading, Computers and Geotechnics 38(4): 430-447.

De Gennaro, V. and Frank, R. (2002). Elasto-plastic analysis of the interface behaviour between granular media and structure, Computers and Geotechnics 29(7): 547-572.

De Moel, M., Bach, P. M., Bouazza, A., Singh, R. M. and Sun, J. O. (2010). Technological advances and applications of geothermal energy pile foundations and their feasibility in australia, Renewable and Sustainable Energy Reviews 14(9): 2683-2696.

DeJong, J. T., Randolph, M. F. and White, D. J. (2003). Interface load transfer degradation during cyclic loading: a microscale investigation, Soils and foundations 43(4): 81-93.

Desai, C., Drumm, E. and Zaman, M. (1985). Cyclic testing and modeling of interfaces, Journal of Geotechnical Engineering 111(6): 793-815. 
Di Donna, A., Ferrari, A. and Laloui, L. (2015). Experimental investigations of the soil-concrete interface: physical mechanisms, cyclic mobilization, and behaviour at different temperatures, Canadian Geotechnical Journal 53(4): 659-672.

Faizal, M., Bouazza, A., Haberfield, C. and McCartney, J. S. (2018). Axial and radial thermal responses of a field-scale energy pile under monotonic and cyclic temperature changes, Journal of Geotechnical and Geoenvironmental Engineering 144(10): 04018072.

Fakharian, K. and Evgin, E. (1997). Cyclic simple-shear behavior of sand-steel interfaces under constant normal stiffness condition, Journal of Geotechnical and Geoenvironmental Engineering 123(12): 10961105.

Fakharian, K. and Evgin, E. (2000). Elasto-plastic modelling of stress-path-dependent behaviour of interfaces, International Journal for Numerical and Analytical Methods in Geomechanics 24(2): 183199.

Ghionna, V. N. and Mortara, G. (2002). An elastoplastic model for sand - structure interface behaviour.

Graham, J., Tanaka, N., Crilly, T. and Alfaro, M. (2001). Modified cam-clay modelling of temperature effects in clays, Canadian geotechnical journal 38(3): 608-621.

Hamidi, a. and Khazaei, C. (2010). A thermo-mechanical constitutive model for saturated clays, International Journal of Geotechnical Engineering 4: 445-459.

Houston, S. L. and Lin, H.-D. (1987). A thermal consolidation model for pelagic clays, Marine Georesources \& Geotechnology 7(2): 79-98.

Hueckel, T. and Baldi, G. (1990). Thermoplasticity of saturated clays: experimental constitutive study, Journal of geotechnical engineering 116(12): 1778-1796.

Hueckel, T. and Borsetto, M. (1990). Thermoplasticity of saturated soils and shales: constitutive equations, Journal of Geotechnical Engineering 116(12): 1765-1777.

Hueckel, T., François, B. and Laloui, L. (2009). Explaining thermal failure in saturated clays, Géotechnique 59(3): 197-212.

Hueckel, T., Pellegrini, R. and Del Olmo, C. (1998). A constitutive study of thermo-elasto-plasticity of deep carbonatic clays, International journal for numerical and analytical methods in geomechanics 22(7): 549-574.

Kuntiwattanakul, P., Towhata, I., Ohishi, K. and Seko, I. (1995). Temperature effects on undrained shear characteristics of clay, Soils and Foundations 35(1): 147-162.

Kuo, M. and Bolton, M. (2014). Shear tests on deep-ocean clay crust from the gulf of guinea, Géotechnique 64(4): 249-257.

Kuo, M., Vincent, C., Bolton, M., Hill, A. and Rattley, M. (2015). A new torsional shear device for pipeline interface shear testing, Proceedings of 3rd International Symposium on Frontiers in Offshore Geotechnics, Taylor \& Francis Group, London, UK, pp. 405-410.

Laguros (1969). Effect of temperature on some engineering properties of clay soils, Special Report 103, Washington D.C. .

Lahoori, M., Jannot, Y., Rosin-Paumier, S., Boukelia, A. and Masrouri, F. (2020). Measurement of the thermal properties of unsaturated compacted soil by the transfer function estimation method, Applied Thermal Engineering 167: 114795.

Laloui, L. and François, B. (2009). Acmeg-t: soil thermoplasticity model, Journal of engineering mechanics 135(9): 932-944.

Laloui, L., Nuth, M. and Vulliet, L. (2006). Experimental and numerical investigations of the behaviour of a heat exchanger pile, International Journal for Numerical and Analytical Methods in Geomechanics 30(8): 763-781.

Lashkari, A. (2013). Prediction of the shaft resistance of nondisplacement piles in sand, International Journal for Numerical and Analytical Methods in Geomechanics 37(8): 904-931.

Lashkari, A. (2017). A simple critical state interface model and its application in prediction of shaft resistance of non-displacement piles in sand, Computers and Geotechnics 88: 95-110.

Lemos, L. and Vaughan, P. (2000). Clay-interface shear resistance, Géotechnique 50(1): 55-64. 
Li, C., Kong, G., Liu, H. and Abuel-Naga, H. (2018). Effect of temperature on behaviour of red claystructure interface, Canadian Geotechnical Journal 56(1): 126-134.

Liu, H., Liu, H., Xiao, Y. and McCartney, J. S. (2018). Effects of temperature on the shear strength of saturated sand, Soils and Foundations 58(6): 1326-1338.

Liu, H., Song, E. and Ling, H. I. (2006). Constitutive modeling of soil-structure interface through the concept of critical state soil mechanics, Mechanics Research Communications 33(4): 515-531.

Loveridge, F., McCartney, J. S., Narsilio, G. A. and Sanchez, M. (2020). Energy geostructures: a review of analysis approaches, in situ testing and model scale experiments, Geomechanics for Energy and the Environment 22: 100173.

Maghsoodi, S. (2020). Thermo-mechanical behavior of soil-structure interface under monotonic and cyclic loads in the context of energy geostructures, $\mathrm{PhD}$ thesis, Université de Lorraine.

Maghsoodi, S., Cuisinier, O. and Masrouri, F. (2019). Thermo-mechanical behaviour of clay-structure interface, E3S Web of Conferences, Vol. 92, EDP Sciences, p. 10002.

Maghsoodi, S., Cuisinier, O. and Masrouri, F. (2020a). Effect of temperature on the cyclic behavior of clay-structure interface, Journal of Geotechnical and Geoenvironmental Engineering 146(10): 04020103.

Maghsoodi, S., Cuisinier, O. and Masrouri, F. (2020b). Thermal effects on mechanical behaviour of soilstructure interface, Canadian geotechnical journal 57(1): 32-47.

URL: https://doi.org/10.1139/cgj-2018-0583

Maghsoodi, S., Cuisinier, O. and Masrouri, F. (2020c). Thermal effects on one-way cyclic behaviour of clay-structure interface, E3S Web of Conferences, Vol. 205, EDP Sciences, p. 05001.

URL: $h$ ttps://doi.org/10.1051/e3sconf/202020505001

Martinez, A., Frost, J. D. and Hebeler, G. L. (2015). Experimental study of shear zones formed at sand/steel interfaces in axial and torsional axisymmetric tests, Geotechnical Testing Journal 38(4): 409426 .

Martinez, A. and Stutz, H. H. (2018). Rate effects on the interface shear behaviour of normally and over-consolidated clay, Géotechnique.

Mašín, D. and Khalili, N. (2011). Modelling of thermal effects in hypoplasticity, Proceedings of the 13th International Conference of the IACMAG, Melbourne, Australia, Vol. 1, pp. 237-245.

Mašín, D. and Khalili, N. (2012). A thermo-mechanical model for variably saturated soils based on hypoplasticity, International journal for numerical and analytical methods in geomechanics 36(12): 14611485.

McCartney, J. S. and Rosenberg, J. E. (2011). Impact of heat exchange on side shear in thermo-active foundations, Geo-Frontiers 2011: Advances in Geotechnical Engineering, pp. 488-498.

Mortara, G., Boulon, M. and Ghionna, V. N. (2002). A 2-d constitutive model for cyclic interface behaviour, International journal for numerical and analytical methods in geomechanics 26(11): 10711096.

Murayama (1969). Effect of temperature on the elasticity of clays, Special Report 103, Washington D.C.

Murphy, K. D., McCartney, J. S. and Henry, K. S. (2015). Evaluation of thermo-mechanical and thermal behavior of full-scale energy foundations, Acta Geotechnica 10(2): 179-195.

Pra-ai, S. and Boulon, M. (2017). Soil-structure cyclic direct shear tests: a new interpretation of the direct shear experiment and its application to a series of cyclic tests, Acta Geotechnica 12(1): 107-127.

Saberi, M., Annan, C.-D. and Konrad, J.-M. (2017). Constitutive modeling of gravelly soil-structure interface considering particle breakage, Journal of Engineering Mechanics 143(8): 04017044.

Saberi, M., Annan, C.-D., Konrad, J.-M. and Lashkari, A. (2016). A critical state two-surface plasticity model for gravelly soil-structure interfaces under monotonic and cyclic loading, Computers and Geotechnics 80: 71-82.

Sadrekarimi, A. and Olson, S. M. (2010). Shear band formation observed in ring shear tests on sandy soils, Journal of geotechnical and geoenvironmental engineering 136(2): 366-375. 
Shahrour, I. and Rezaie, F. (1997). An elastoplastic constitutive relation for the soil-structure interface under cyclic loading, Computers and Geotechnics 21(1): 21-39.

Sherif, M. A. and Burrous, C. M. (1969). Temperature effects on the unconfined shear strength of saturated, cohesive soil, Highway Research Board Special Report (103).

Stutz, H. and Mašín, D. (2017). Hypoplastic interface models for fine-grained soils, International Journal for numerical and analytical methods in geomechanics 41(2): 284-303.

Stutz, H., Mašín, D. and Wuttke, F. (2016). Enhancement of a hypoplastic model for granular soilstructure interface behaviour, Acta Geotechnica 11(6): 1249-1261.

Stutz, H., Mašín, D., Wuttke, F. and Prädel, B. (2016). Thermo-mechanical hypoplastic interface model for fine-grained soils, Proceedings of the 1st International Conference on Energy Geotechnics, pp. 351357.

Suryatriyastuti, M., Mroueh, H. and Burlon, S. (2014). A load transfer approach for studying the cyclic behavior of thermo-active piles, Computers and Geotechnics 55: 378-391.

Tang, A.-M. and Cui, Y.-J. (2009). Modelling the thermo-mechanical volume change behaviour of compacted expansive clays, arXiv preprint arXiv:0904.3614.

Tsubakihara, Y. and Kishida, H. (1993). Frictional behaviour between normally consolidated clay and steel by two direct shear type apparatuses, Soils and Foundations 33(2): 1-13.

Yao, Y. and Zhou, A. (2013). Non-isothermal unified hardening model: a thermo-elasto-plastic model for clays, Geotechnique 63(15): 1328 .

Yavari, N. (2014). Aspects géotechniques des pieux de fondation énergétiques, $\mathrm{PhD}$ thesis, Paris Est.

Yavari, N., Tang, A. M., Pereira, J.-M. and Hassen, G. (2016). Effect of temperature on the shear strength of soils and the soil-structure interface, Canadian Geotechnical Journal 53(7): 1186-1194.

Yazdani, S., Helwany, S. and Olgun, G. (2019). Influence of temperature on soil-pile interface shear strength, Geomechanics for Energy and the Environment 18: 69-78.

\section{List of symbols}

- $e(-) \quad$ Void ratio

- $e_{i n}(-) \quad$ Initial void ratio

- $e_{i n}(T)(-) \quad$ Initial void ratio at temperature $T$

- $e_{c s}(-) \quad$ Critical state void ratio

- $\epsilon(-)$ Shear strain (in direct shear test)

- $W(m m)$ Shear displacement (in direct shear test)

- $\xi\left(m^{-1}\right)$ Controls the rate of void ratio evolution

- $k_{1}^{*}\left(\mathrm{~mm}^{-1}\right)$ intensifies the initial contraction

- $k_{2}(\mathrm{kPa} / \mathrm{mm})$ parameter of the model

- $K(\mathrm{kPa} / \mathrm{mm}) \quad$ Stiffness

- $t(m m)$ Interface thickness

- $\Gamma(-) \quad$ Initial critical void ratio

- $\lambda(-) \quad$ Slope of the critical void ratio reduction with normal stress

- $\mu(k P a) \quad$ Elastic shear modulus

- $k_{t 0}(k P a / m m)$ slope of the initial part of the $\tau-w$ curve

- $M(-) \quad$ Slope of the $\tau / \sigma_{n}$

- $N$ Controls the peak and the strain softening

- $\psi$ Controls the rate of volumetric evolution

- $\alpha\left({ }^{\circ} C^{-1}\right)$ Slope of the void ratio evolution with temperature

- $T\left({ }^{\circ} C\right)$ Temperature

- $\beta(-)$ Controls the effect of normal stress

- CNL Constant normal load 
- CNS Constant normal stiffness

- $\tau(k P a)$ Shear stress

- $\sigma_{n}^{\prime}(k P a)$ Effective normal stress

- $U(m m) \quad$ Normal displacement

- $R_{\max }(\mathrm{mm}) \quad$ Maximum surface roughness

- $\delta\left(^{\circ}\right)$ friction angle of interface

- $D_{50}(\mathrm{~mm})$ mean diameter of soil particles

- $\rho_{s}\left(\mathrm{~g} / \mathrm{cm}^{3}\right)$ grain density of soil particles

- $\rho_{\text {dmax }}\left(k N / m^{3}\right)$ maximum dry density

- $\rho_{\text {dmin }}\left(k N / m^{3}\right)$ minimum dry density

- $e_{\max }$ maximum void ratio

- $e_{\min }$ minimum void ratio

- $C_{u}=D_{60} / D_{10} \quad$ coefficient of uniformity

- $k(m / s)$ hydraulic conductivity

- $L L(\%)$ Liquid limit

- $P L(\%) \quad$ Plastic limit

- $P I(\%)$ Plasticity index

${ }_{656}-\lambda(W / m K) \quad$ Thermal conductivity

${ }_{657} C\left(J / m^{3} K\right) \quad$ Heat capacity 


\section{List of Tables}

1 Constitutive equations of Lashkari (2017) model. . . . . . . . . . . . . . . . . . . . . . . 19

2 Model parameters of this study. . . . . . . . . . . . . . . . . . . . . . . . 20

3 Physical properties of sands in this study . . . . . . . . . . . . . . . . . . . . . 21

4 Physical properties of clays in this study . . . . . . . . . . . . . . . . . . . . . . 22

\section{List of Figures}

$1 \mathrm{CNL}(\mathrm{K}=0 \mathrm{kPa} / \mathrm{mm})$ and $\mathrm{CNS}(\mathrm{K}=1000 \mathrm{kPa} / \mathrm{mm})$ clay-structure interface results for 100 and $300 \mathrm{kPa}$ at 22 and $60{ }^{\circ} \mathrm{C}$ (Maghsoodi et al. (2019)). . . . . . . . . . . . . . . 23

2 (a) Thermal vertical strain vs. temperature for clay-structure interface under $300 \mathrm{kPa}$. (b) The void ratio evolution during shearing under $100 \mathrm{kPa}$ at 22 and $60{ }^{\circ} \mathrm{C}$. . . . . . . . .

3 Evolution of void ratio during shearing using Eq. 1: (a) different initial void ratios $\left(e_{i n}=\right.$ $0.7,0.8,0.9,1.0,1.1$ and 1.2$)$ evolution towards the critical state void ratio $\left(e_{c s}=0.824\right)$; (b) Void ratio evolution for a loose and dense Fontainebleau sand-structure interface test performed by Pra-ai and Boulon (2017) . . . . . . . . . . . . . . .

4 Void ratio reduction during heating kaolin clay-interface test. Experimental data by Magh-

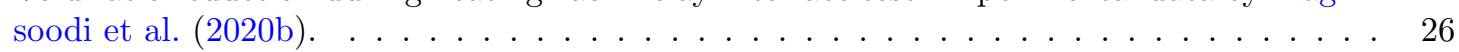

5 Model parameter definitions. . . . . . . . . . . . . . . . . . . . .

6 model performance and parametric study: (a) variation of shear stress-displacement response with different $k t_{0}$, (b) variation of shear stress-displacement response with different $N$, (c) normal displacement response to different $\Gamma$ values (d) normal displacement response to different $\lambda$ values (e) normal displacement response to different $\xi$ values, (f) variation of shear stress-displacement response with different $\xi$, $(\mathrm{g})$ variation of shear stress-displacement response with different $k_{2},(\mathrm{~h})$ variation of shear stress-displacement response with different $\beta$ and (i) variation of shear stress versus shear displacement for different temperatures $T$. . . . . . . . . . . . . . . . . . . . .

$7 \quad$ Model performance against CNL Fontainebleau sand-structure interface test results under 100, 200 and $300 \mathrm{kPa}$ of normal stress at $22^{\circ} \mathrm{C}$. (a) shear stress vs. shear displacement; and (b) normal displacement vs. shear displacement (experimental data by Maghsoodi et al. $(2020 \mathrm{~b})) . \ldots \ldots \ldots \ldots \ldots \ldots \ldots \ldots$

8 Model performance against $\operatorname{CNS}\left(\sigma_{n 0}=100 \mathrm{kPa}, K=1000,5000 \mathrm{kPa} / \mathrm{mm}\right)$ Fontainebleau sand-structure interface test results under $100 \mathrm{kPa}$ of normal stress at $22^{\circ} \mathrm{C}$. (a) shear stress vs. shear displacement; and (b) normal displacement vs. shear displacement (experimental data by Maghsoodi et al. (2020b)). . . . . . . . . . . . . . . . . . .

9 Model performance against CNS $\left(\sigma_{n 0}=100,200,300 \mathrm{kPa}, K=1000 \mathrm{kPa} / \mathrm{mm}\right)$ Fontainebleau sand-structure interface test results under $100 \mathrm{kPa}$ of normal stress at $22^{\circ} \mathrm{C}$. (a) shear stress vs. shear displacement; and (b) normal displacement vs. shear displacement (experimental data by Maghsoodi et al. (2020b)). . . . . . . . . . . . . . . . . . . . .

10 The interface model predictions against experimental data for CNL $\left(\sigma_{n}=50,100,150 \mathrm{kPa}\right)$ and CNS tests $(\mathrm{K}=1000 \mathrm{kPa} / \mathrm{mm})$ on quartz sand-concrete interface: (a) shear stress vs. shear displacement; and (b) normal displacement vs. shear displacement; (c) normal stress vs. shear displacement (experimental data by Di Donna et al. (2015)) . . . . . . . . . . .

11 The interface model predictions against experimental data for four constant normal stress tests $(K=0)$ on interfaces between Fontainebleau sand and steel: (a) shear stress vs. shear displacement; and (b) normal displacement vs. shear displacement (experimental data by De Gennaro and Frank (2002)) . . . . . . . . . . . . . . . . . . . . . 
12 The interface model predictions against experimental data for four constant normal stress tests $(\mathrm{K}=0)$ on interfaces between Fontainebleau sand and steel: (a) shear stress vs. shear displacement; and (b) normal displacement vs. shear displacement (experimental data by Fakharian and Evgin (2000)). . . . . . . . . . . . . . . .

13 The interface model predictions against experimental data for four constant normal stress tests $(\mathrm{K}=0)$ on interfaces between illite clay and concrete: (a) shear stress vs. shear displacement; and (b) normal displacement vs. shear displacement (experimental data by Di Donna et al. (2015)). . . . . . . . . . . . . . . . . . . . .

14 The interface model predictions against experimental data for four constant normal stress tests $(K=0)$ on interfaces between illite clay and concrete: (a) shear stress vs. shear displacement; and (b) normal displacement vs. shear displacement (experimental data by Yazdani et al. (2019)). . . . . . . . . . . . . . . . . . . . . .

15 The interface model predictions against experimental data for four constant normal stress tests $(K=0)$ on interfaces between kaolin clay and steel: (a)(c) shear stress vs. shear displacement; and (b)(d) normal displacement vs. shear displacement (experimental data by Maghsoodi et al. (2020b)). . . . . . . . . . . . . . . . . . . . . .

16 The interface model predictions against experimental data for four constant normal stiffness tests $(\mathrm{K}=1000 \mathrm{kPa} / \mathrm{mm})$ on interfaces between kaolin clay and steel: (a) shear stress vs. shear displacement; and (b) normal displacement vs. shear displacement (experimental data by Maghsoodi et al. (2020b)) . . . . . . . . . . . . . . . . . . . 
Table 1: Constitutive equations of Lashkari (2017) model.

\begin{tabular}{|c|c|c|c|}
\hline Description & Constitutive equation & Parameters & $\begin{array}{l}\text { Eq. } \\
\mathbf{N}\end{array}$ \\
\hline $\begin{array}{l}\text { Void ratio } \\
\text { evolution }\end{array}$ & $e_{c s}[1-\exp (-\xi \epsilon)]+e_{i n} \exp (-\xi \epsilon)-\frac{k_{1}}{1+K / k_{2}} \epsilon \exp (-\xi \epsilon)$ & $e, e_{i n}, e_{c s}, \epsilon, \xi$ & 1 \\
\hline $\begin{array}{l}\text { Normal stress } \\
\text { evolution }\end{array}$ & $\delta \sigma_{n}^{\prime}=K \delta v$ & $K, \delta v$ & 2 \\
\hline $\begin{array}{l}\text { Normal stress } \\
\text { evolution }\end{array}$ & $\delta \sigma_{n}^{\prime}=-K \delta v=\frac{-K t \delta e}{1+e}$ & $K, t, e$ & 3 \\
\hline $\begin{array}{l}\text { Critical state } \\
\text { void ratio }\end{array}$ & $e_{c s}=\Gamma-\lambda \ln \left(\sigma_{n}^{\prime} / p_{\text {ref }}\right)$ & $\Gamma, \lambda$ & 4 \\
\hline State parameter & $\psi=e-e_{c s}$ & $e, e_{c s}$ & 5 \\
\hline $\begin{array}{l}\text { Shear stress } \\
\text { evolution }\end{array}$ & $\tau=\frac{\epsilon}{\frac{1}{\mu}+\frac{\epsilon}{M \sigma_{n}[1+N\langle-\psi\rangle]}}$ & $M, \mu, \sigma_{n}, N, \psi$ & 6 \\
\hline
\end{tabular}


Table 2: Model parameters of this study.

\begin{tabular}{|c|c|c|c|c|c|c|c|c|c|c|c|c|c|c|c|}
\hline $\begin{array}{c}\text { Interface } \\
\text { type }\end{array}$ & Reference & $\begin{array}{l}k t \\
\frac{k P a}{m m} \\
\end{array}$ & $\begin{array}{c}\delta \\
(o) \\
\end{array}$ & $\begin{array}{l}\Gamma \\
(-)\end{array}$ & $\begin{array}{l}\lambda \\
(-) \\
\end{array}$ & $\begin{array}{l}\xi^{*} \\
(-)\end{array}$ & $\begin{array}{l}\mathrm{N} \\
(-)\end{array}$ & $\begin{array}{c}\mathrm{K} \\
\frac{k P a}{m m} \\
\end{array}$ & $\begin{array}{l}\mathrm{k}_{1} \\
(-)\end{array}$ & $\begin{array}{l}\mathrm{k}_{2} \\
\frac{k P a}{m m} \\
\end{array}$ & $\begin{array}{c}\mathrm{t} \\
(\mathrm{mm})\end{array}$ & $\begin{array}{l}\mathrm{T} \\
\left({ }^{o} C\right)\end{array}$ & $\begin{array}{l}\mathrm{C} \\
(\mathrm{kPa})\end{array}$ & $\begin{array}{l}\beta \\
(-)\end{array}$ & $\begin{array}{l}R_{n} \\
(-) \\
\end{array}$ \\
\hline $\begin{array}{c}\text { Fontainebleau } \\
\text { sand- } \\
\text { structure }\end{array}$ & $\begin{array}{c}\text { Maghsoodi } \\
\text { et al. } \\
\text { (2020b) } \\
\text { (CNL) }\end{array}$ & 208 & 40 & 0.835 & 0.040 & 1.58 & 2.2 & 0 & 0.5 & 0.5 & 1.15 & 22 & 0 & 0.94 & 0.32 \\
\hline $\begin{array}{c}\text { Fontainebleau } \\
\text { sand- } \\
\text { structure }\end{array}$ & $\begin{array}{c}\text { Maghsoodi } \\
\text { et al. } \\
\text { (2020b) } \\
\text { (CNS) }\end{array}$ & 208 & 40 & 0.67 & 0.040 & 1.58 & 2.2 & 5000 & 3000 & 0.5 & 1.15 & 22 & 0 & 0.94 & 0.32 \\
\hline $\begin{array}{l}\text { Quartz sand- } \\
\text { concrete }\end{array}$ & $\begin{array}{l}\text { Di Donna } \\
\text { et al. }(2015) \\
(\mathbf{C N L})\end{array}$ & 400 & 40 & 0.70 & 0.030 & 1.6 & 2 & 0 & 0.2 & 0.3 & 1 & 22 & 0 & 0.89 & 0.2 \\
\hline $\begin{array}{l}\text { Quartz sand- } \\
\text { concrete }\end{array}$ & $\begin{array}{l}\text { Di Donna } \\
\text { et al. }(2015) \\
(\mathbf{C N S})\end{array}$ & 400 & 40 & 0.68 & 0.030 & 1.6 & 2 & 1000 & 800 & 0.3 & 1 & 22 & 0 & 0.93 & 0.2 \\
\hline $\begin{array}{c}\text { Fontainebleau } \\
\text { sand-steel }\end{array}$ & $\begin{array}{c}\text { De Gennaro } \\
\text { and Frank } \\
(2002) \\
\text { (CNL) }\end{array}$ & 208 & 40 & 0.815 & 0.040 & 1.58 & 1.7 & 0 & 0.21 & 0.11 & 1.15 & 22 & 0 & 0.91 & 1 \\
\hline $\begin{array}{c}\text { Silica } \\
\text { sand-steel }\end{array}$ & $\begin{array}{c}\text { Fakharian } \\
\text { and Evgin } \\
(2000) \\
(\mathbf{C N L}) \\
\end{array}$ & 280 & 40 & 0.985 & 0.140 & 1.58 & 1 & 0 & 0.51 & 0.51 & 3 & 22 & 0 & 0.900 & 0.41 \\
\hline $\begin{array}{c}\text { Silica } \\
\text { sand-steel }\end{array}$ & $\begin{array}{c}\text { Fakharian } \\
\text { and Evgin } \\
(2000) \\
\text { (CNS) }\end{array}$ & 280 & 40 & 0.955 & 0.140 & 1.58 & 1 & 400 & 300 & 0.51 & 3 & 22 & 0 & 0.940 & 0.41 \\
\hline $\begin{array}{l}\text { kaolin clay- } \\
\text { structure }\end{array}$ & $\begin{array}{l}\text { Maghsoodi } \\
\text { et al. } \\
\text { (2020b) } \\
\text { (CNL) }\end{array}$ & 170 & 14 & 0.96 & 0.15 & 0.7 & 1.85 & 0 & 0.003 & 2 & 4 & 22 & 12 & 0.965 & 80 \\
\hline $\begin{array}{l}\text { kaolin clay- } \\
\text { structure }\end{array}$ & $\begin{array}{c}\text { Maghsoodi } \\
\text { et al. } \\
\text { (2020b) } \\
\text { (CNS) }\end{array}$ & 170 & 14 & 0.97 & 0.15 & 0.7 & 1.85 & 1000 & 0.003 & 2 & 4 & 22 & 12 & 0.965 & 80 \\
\hline $\begin{array}{c}\text { illite } \\
\text { clay-concrete }\end{array}$ & $\begin{array}{l}\text { Di Donna } \\
\text { et al. }(2015) \\
(\mathbf{C N L})\end{array}$ & 300 & 25 & 0.87 & 0.140 & 0.8 & 4 & 0 & 0.003 & 0.7 & 3 & 22 & 7 & 0.96 & 30 \\
\hline $\begin{array}{c}\text { kaolin } \\
\text { clay-concrete }\end{array}$ & $\begin{array}{l}\text { Yazdani } \\
\text { et al. }(2019) \\
(\mathbf{C N L})\end{array}$ & 110 & 11 & 0.927 & 0.131 & 0.42 & 7.85 & 0 & 0.003 & 4 & 3.5 & 24 & 23 & 0.952 & 5.38 \\
\hline
\end{tabular}


Table 3: Physical properties of sands in this study

\begin{tabular}{|c|c|c|c|c|c|c|c|}
\hline Interface type & $\begin{array}{l}D_{50} \\
(m m)\end{array}$ & $\begin{array}{l}\rho_{s} \\
\left(M g / m^{3}\right)\end{array}$ & $\begin{array}{l}\gamma_{d \max } \\
\left(k N / m^{3}\right)\end{array}$ & $\begin{array}{l}\gamma_{\text {dmin }} \\
\left(k N / m^{3}\right)\end{array}$ & $e_{\max }$ & $e_{\min }$ & $\begin{array}{l}C_{u} \\
D_{60} / D_{10}\end{array}$ \\
\hline $\begin{array}{l}\text { Fontaine bleau sand-structure } \\
\text { Maghsoodi et al. (2020b) }\end{array}$ & 0.23 & 2.65 & 17.2 & 14.2 & 0.866 & 0.545 & 1.72 \\
\hline $\begin{array}{l}\text { Fontaine bleau sand-structure } \\
\text { De Gennaro and Frank }(2002)\end{array}$ & 0.23 & 2.67 & 17.2 & 13.8 & 0.94 & 0.54 & 1.78 \\
\hline $\begin{array}{l}\text { Silica sand-structure Fakharian } \\
\text { and Evgin (2000) }\end{array}$ & 0.6 & 2.7 & 16.35 & 13.33 & 1.024 & 0.651 & - \\
\hline
\end{tabular}


Table 4: Physical properties of clays in this study

\begin{tabular}{|c|c|c|c|c|c|c|c|}
\hline Interface type & $L L(\%)$ & $P L(\%)$ & $I_{p}(\%)$ & $\begin{array}{l}\rho_{s} \\
\left(M g / m^{3}\right)\end{array}$ & $\lambda(W / m K)$ & $\begin{array}{l}C \\
\left(J / m^{3} K\right)\end{array}$ & $k(m / s)$ \\
\hline $\begin{array}{l}\text { Kaolin } \\
\text { structure }\end{array}$ & 57 & 33 & 24 & 2.60 & 1.5 & 3.3 & $10^{-8}$ \\
\hline $\begin{array}{l}\text { Illite } \\
\text { concrete }\end{array}$ & 53.4 & 30 & 23.4 & 2.65 & - & - & $\begin{array}{l}2.85 \times \\
10^{-11}\end{array}$ \\
\hline $\begin{array}{l}\text { Kaolin } \\
\text { concrete }\end{array}$ & 45 & 25 & 20 & 2.62 & - & - & - \\
\hline
\end{tabular}



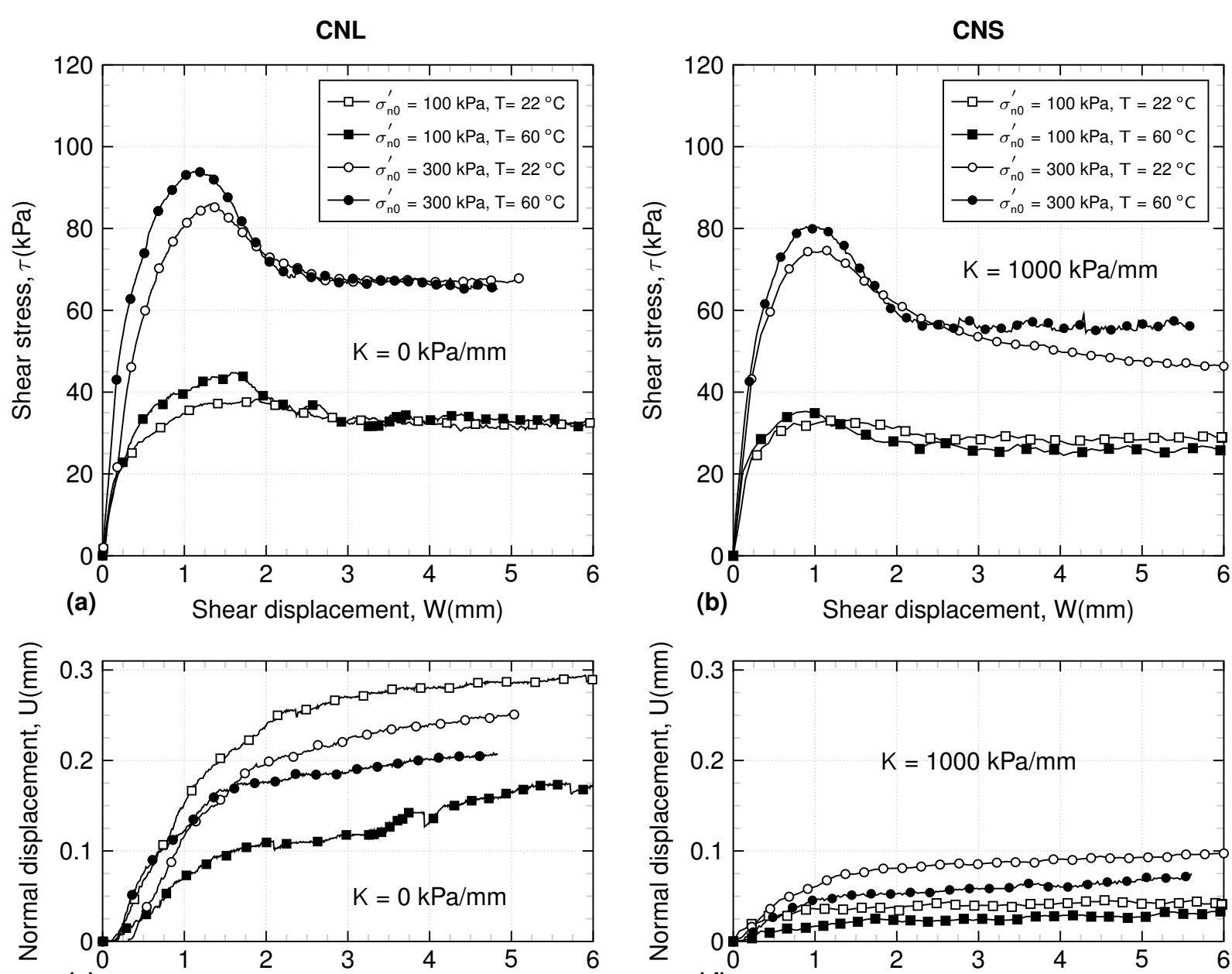

(c) Shear displacement, $\mathrm{W}(\mathrm{mm})$

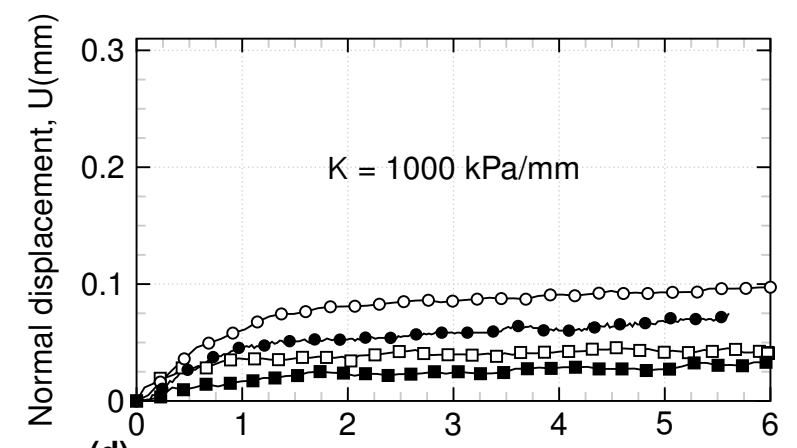

(d) Shear displacement, $\mathrm{W}(\mathrm{mm})$

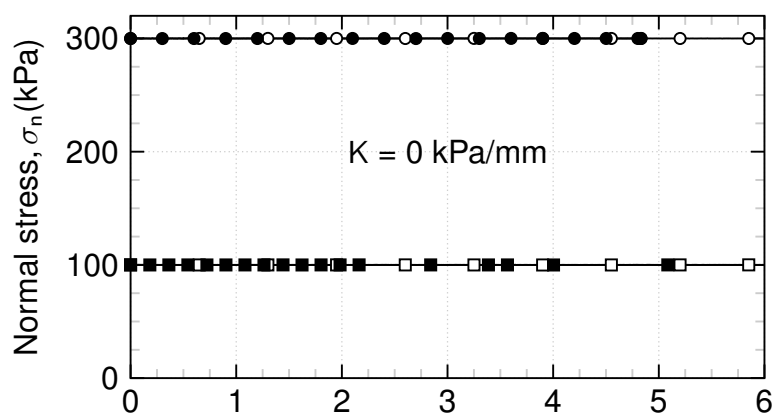

(e) Shear displacement, $\mathrm{W}(\mathrm{mm})$

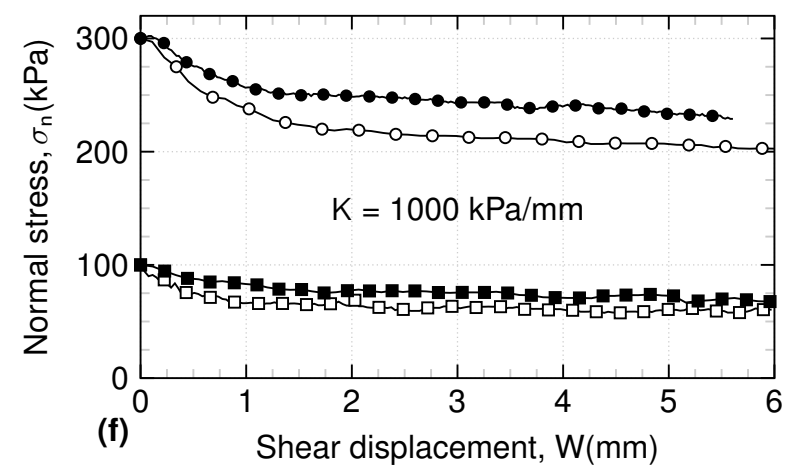

Fig. 1: $C N L(K=0 \mathrm{kPa} / \mathrm{mm})$ and $C N S(K=1000 \mathrm{kPa} / \mathrm{mm})$ clay-structure interface results for 100 and $300 \mathrm{kPa}$ at 22 and $60^{\circ} \mathrm{C}$ (Maghsoodi et al. (2019)). 


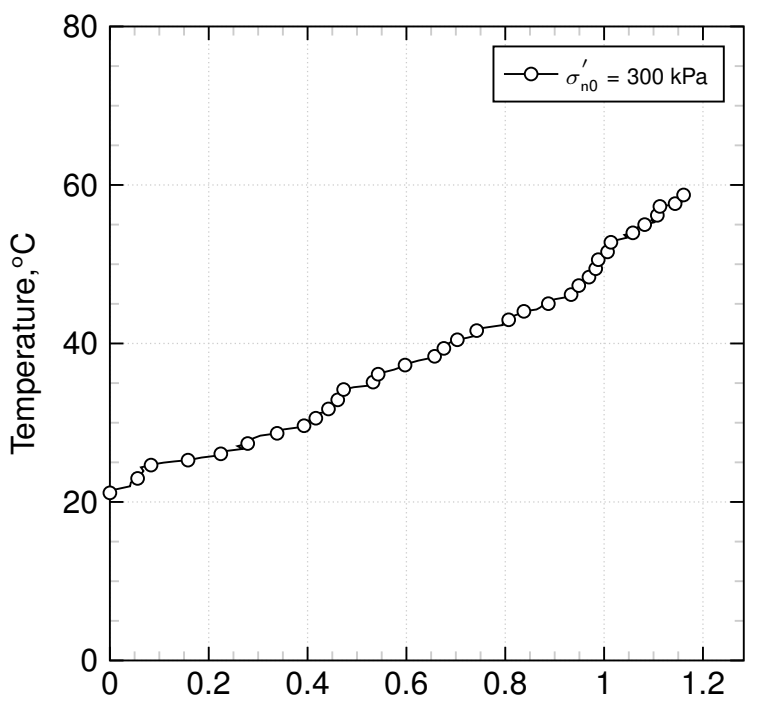

(a)

Thermal vertical strain (\%)

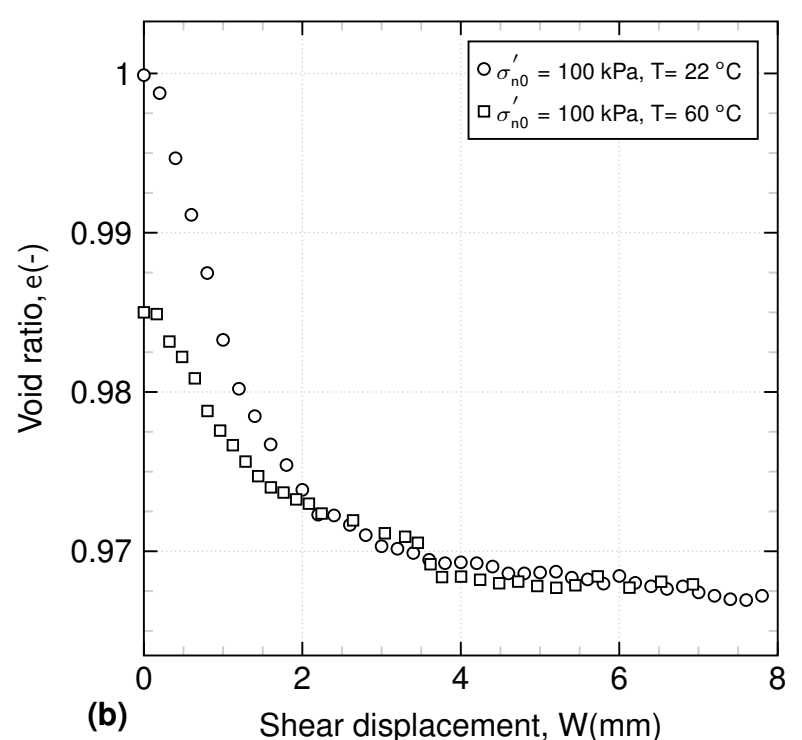

Fig. 2: (a) Thermal vertical strain vs. temperature for clay-structure interface under $300 \mathrm{kPa}$. (b) The void ratio evolution during shearing under $100 \mathrm{kPa}$ at 22 and $60^{\circ} \mathrm{C}$. 

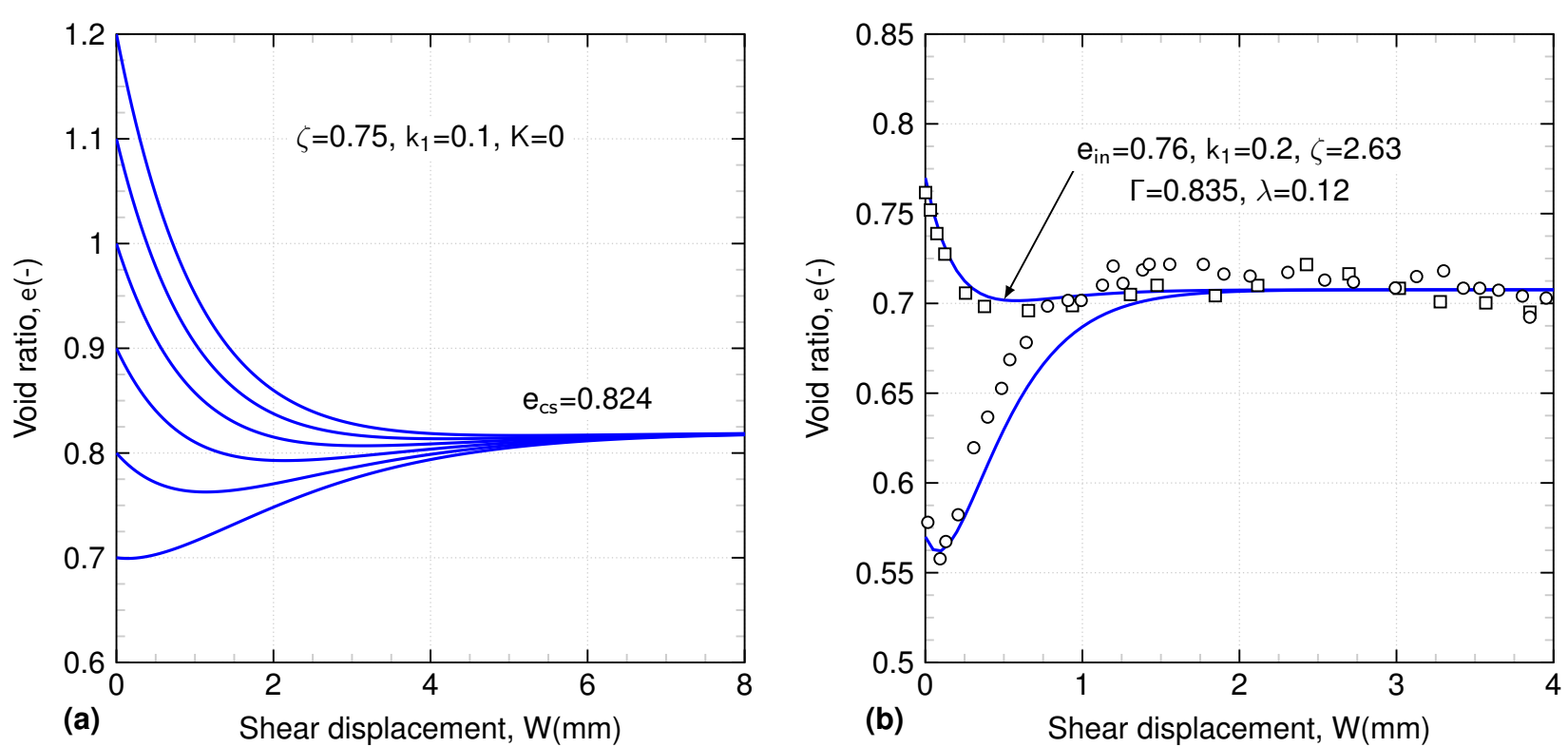

Fig. 3: Evolution of void ratio during shearing using Eq. 1: (a) different initial void ratios (e $e_{i n}=0.7$, 0.8, 0.9, 1.0, 1.1 and 1.2) evolution towards the critical state void ratio ( $\left.e_{c s}=0.824\right)$; (b) Void ratio evolution for a loose and dense Fontainebleau sand-structure interface test performed by Pra-ai and Boulon (2017). 


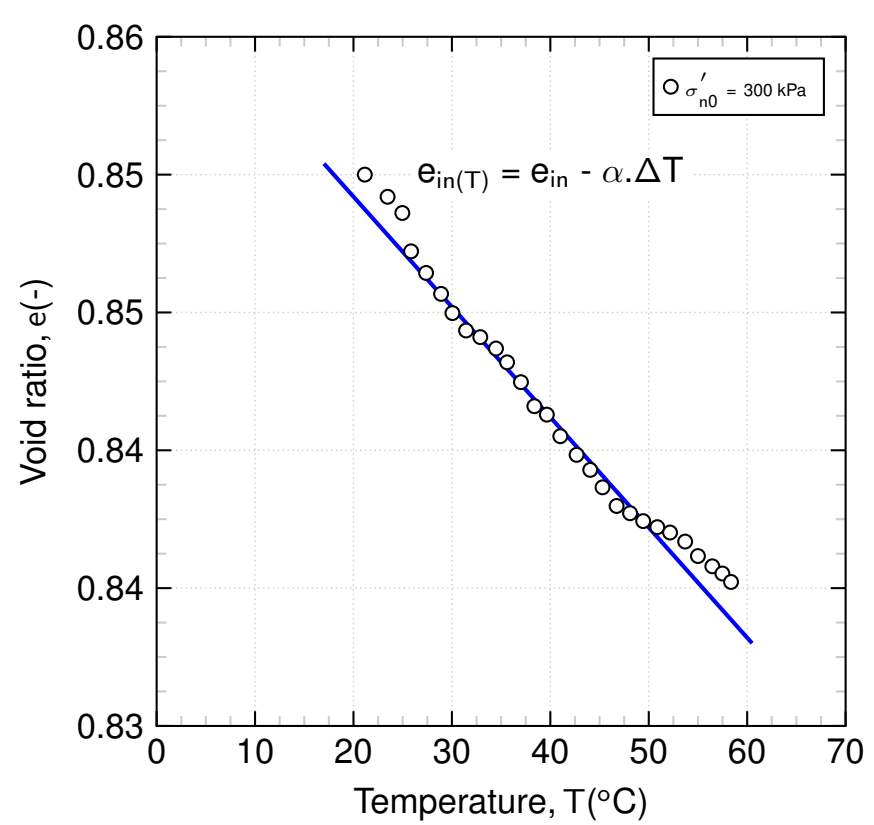

Fig. 4: Void ratio reduction during heating kaolin clay-interface test. Experimental data by Maghsoodi et al. (2020b). 


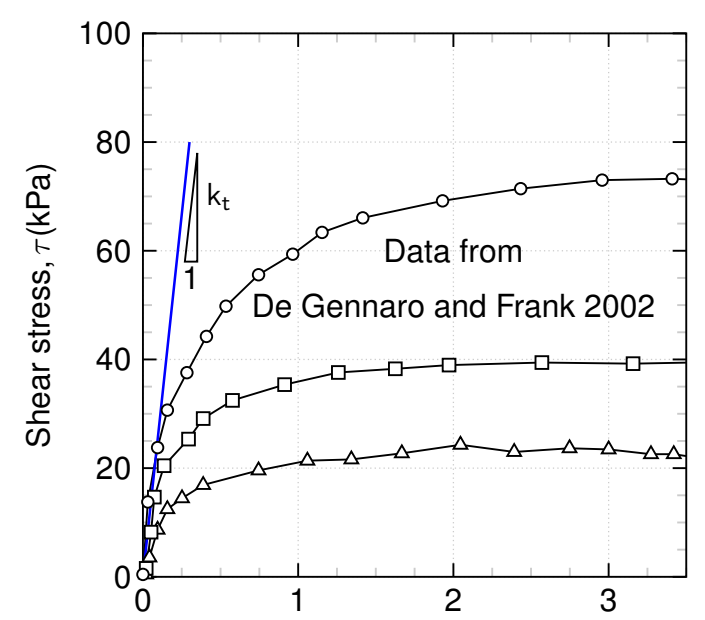

(a) Shear displacement, $\mathrm{W}(\mathrm{mm})$

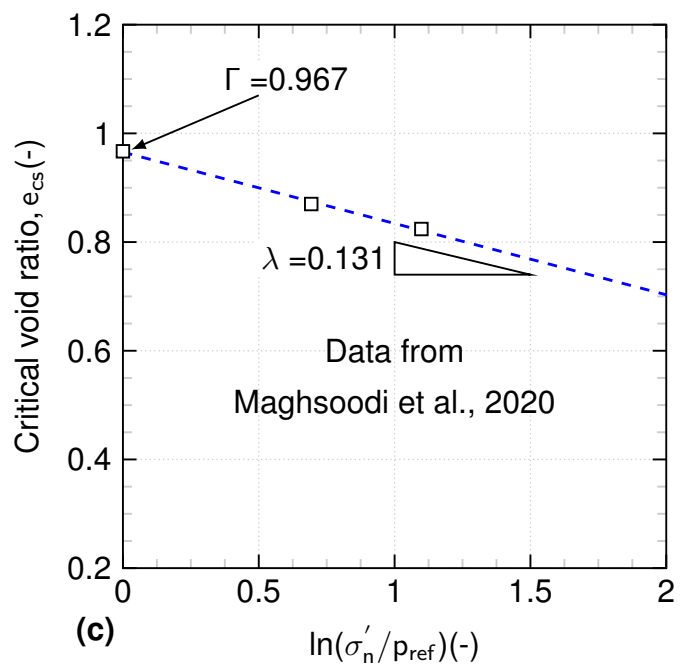

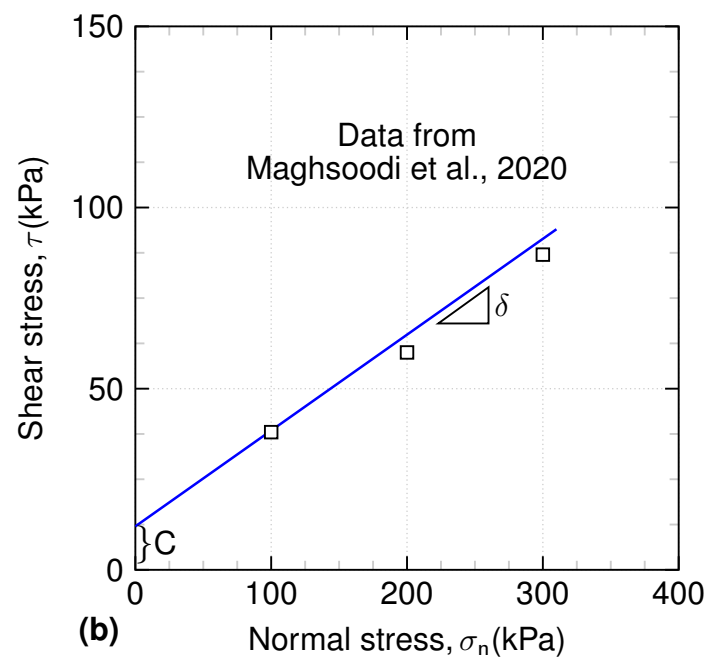

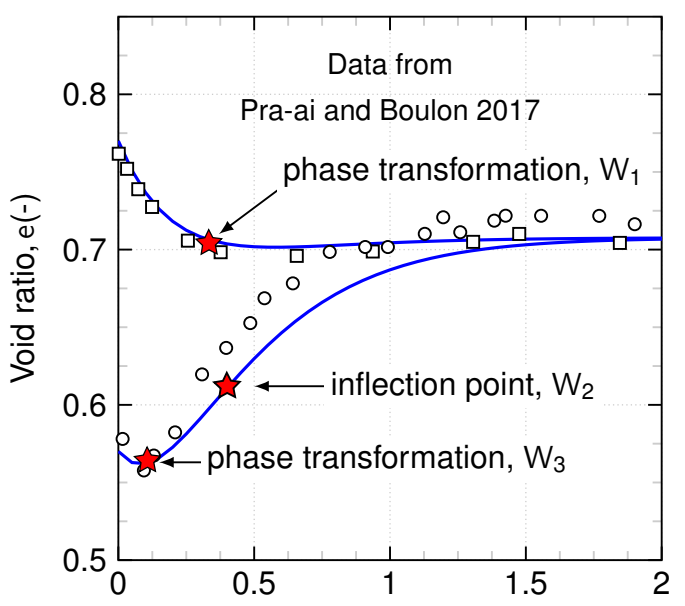

(d) Shear displacement, $\mathrm{W}(\mathrm{mm})$

Fig. 5: Model parameter definitions. 


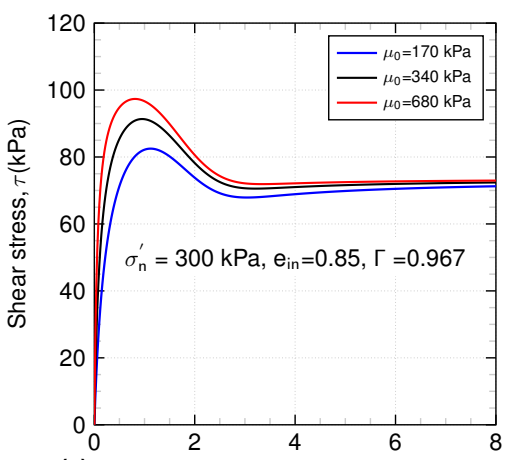

(a) Shear displacement, W(mm)

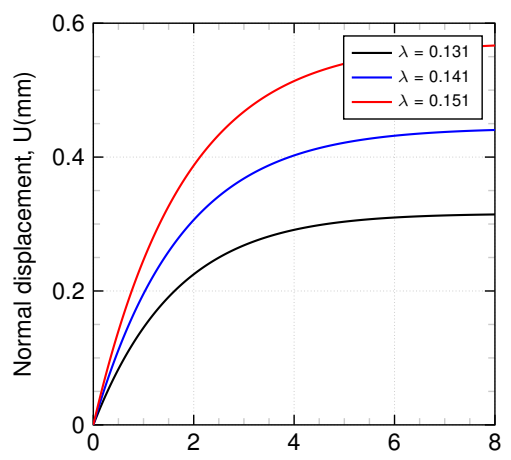

(d) Shear displacement, $\mathrm{W}(\mathrm{mm})$

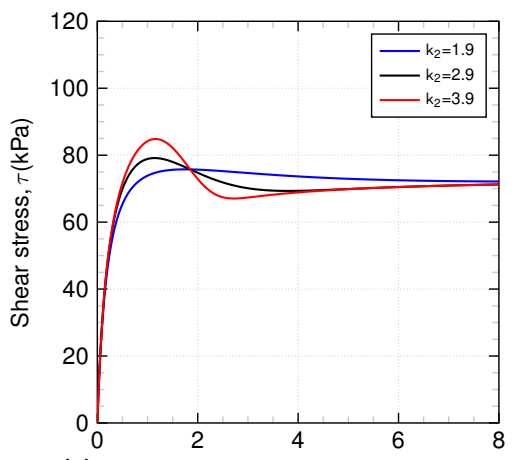

(g) Shear displacement, $\mathrm{W}(\mathrm{mm})$

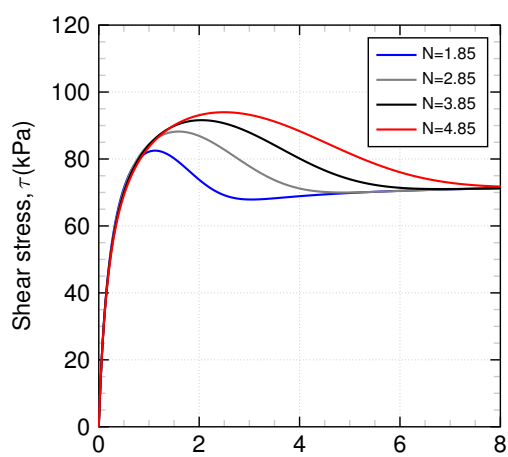

(b) Shear displacement, $\mathrm{W}(\mathrm{mm})$

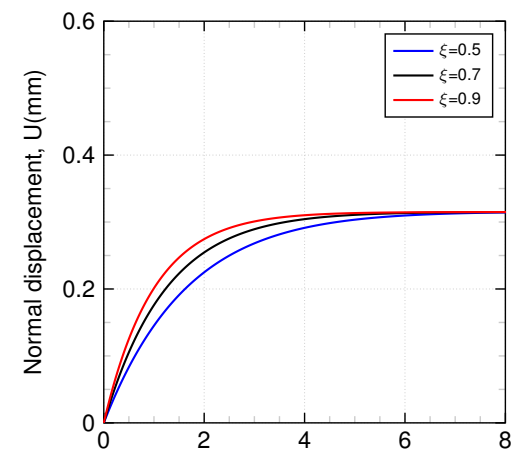

(e) Shear displacement, $\mathrm{W}(\mathrm{mm})$

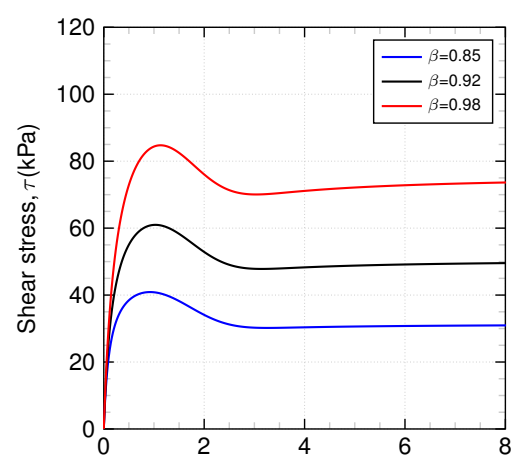

(h) Shear displacement, $\mathrm{W}(\mathrm{mm})$

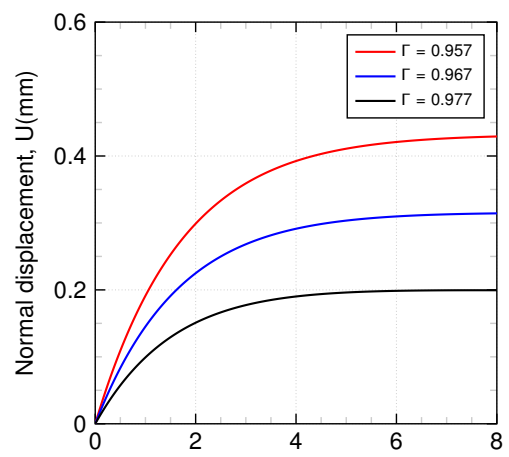

(c) Shear displacement, $\mathrm{W}(\mathrm{mm})$

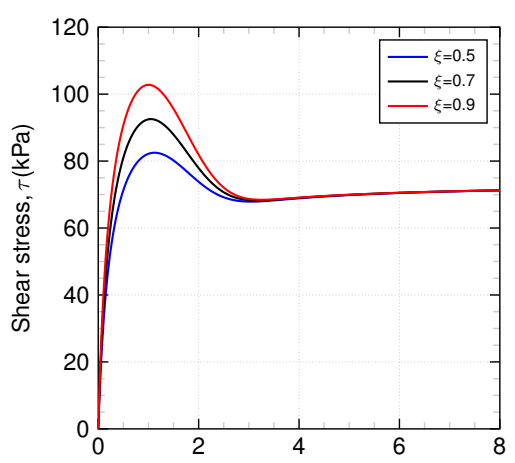

(f) Shear displacement, $\mathrm{W}(\mathrm{mm})$

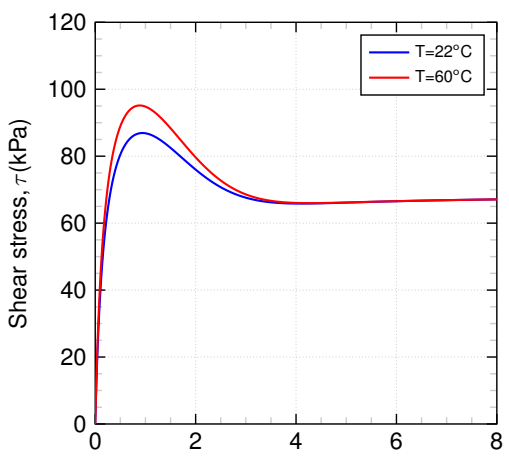

(i) Shear displacement, $\mathrm{W}(\mathrm{mm})$

Fig. 6: model performance and parametric study: (a) variation of shear stress-displacement response with different kt , $_{\text {, }}$ (b) variation of shear stress-displacement response with different $N$, (c) normal displacement response to different $\Gamma$ values (d) normal displacement response to different $\lambda$ values (e) normal displacement response to different $\xi$ values, (f) variation of shear stress-displacement response with different $\xi,(g)$ variation of shear stress-displacement response with different $k_{2}$, ( $h$ ) variation of shear stress-displacement response with different $\beta$ and (i) variation of shear stress versus shear displacement for different temperatures $T$. 


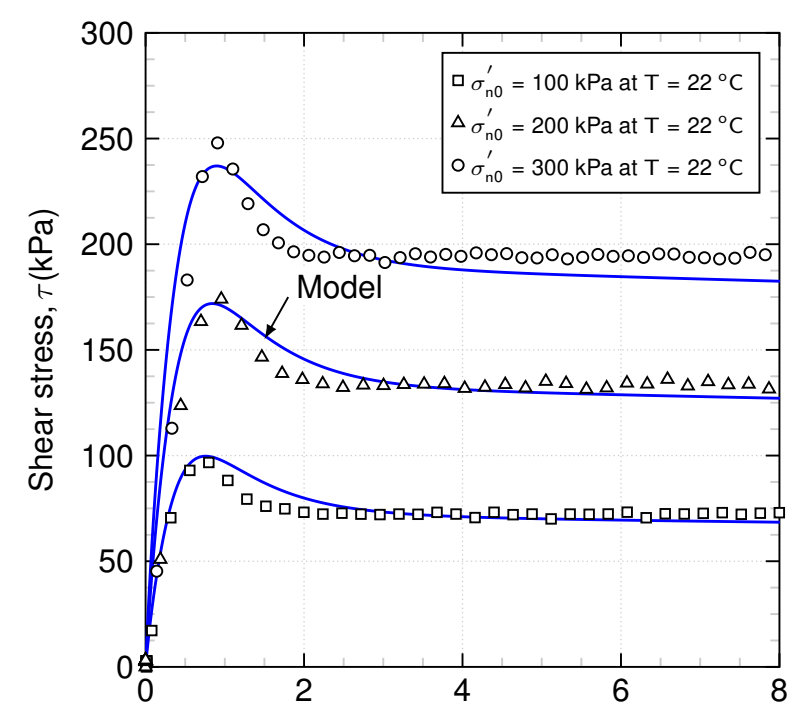

(a) Shear displacement, $\mathrm{W}(\mathrm{mm})$

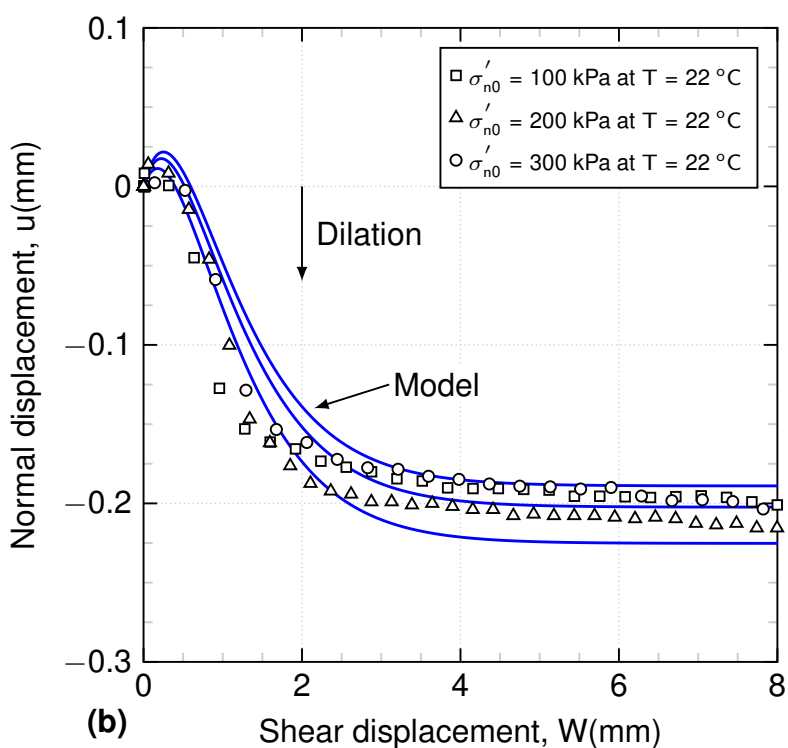

(b) Shear displacement, $\mathrm{W}(\mathrm{mm})$

Fig. 7: Model performance against CNL Fontainebleau sand-structure interface test results under 100, 200 and $300 \mathrm{kPa}$ of normal stress at $22^{\circ} \mathrm{C}$. (a) shear stress vs. shear displacement; and (b) normal displacement vs. shear displacement (experimental data by Maghsoodi et al. (2020b)). 


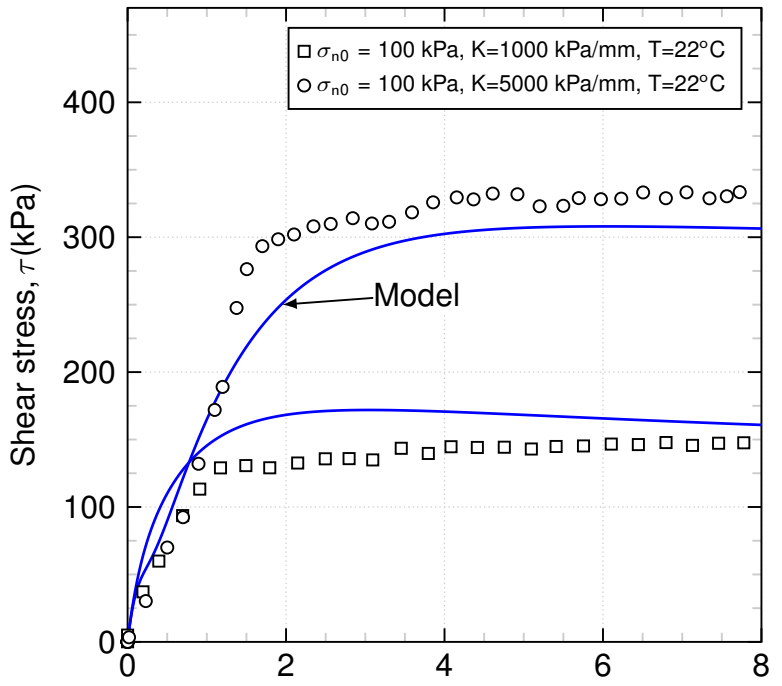

(a) Shear displacement, $\mathrm{W}(\mathrm{mm})$

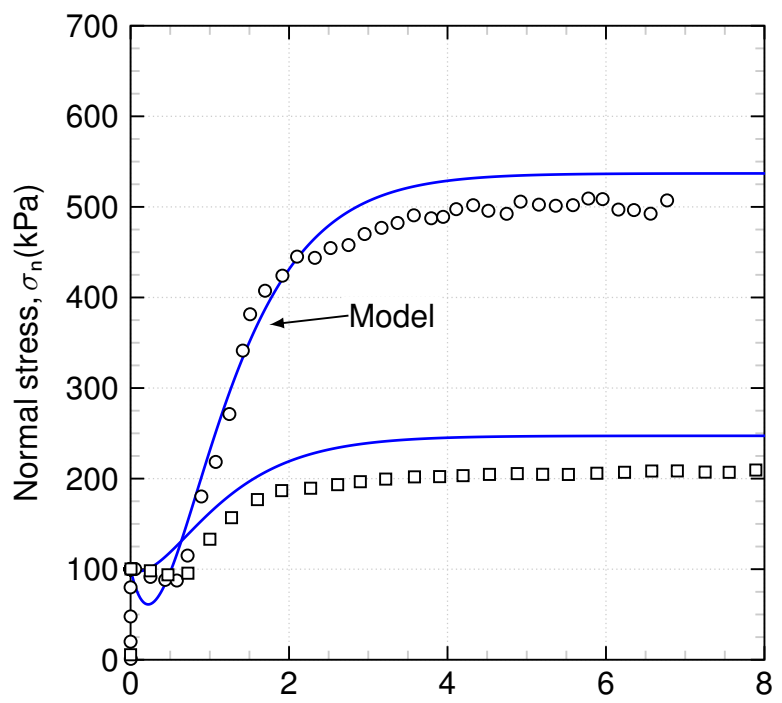

(c)

Shear displacement, $\mathrm{W}(\mathrm{mm})$

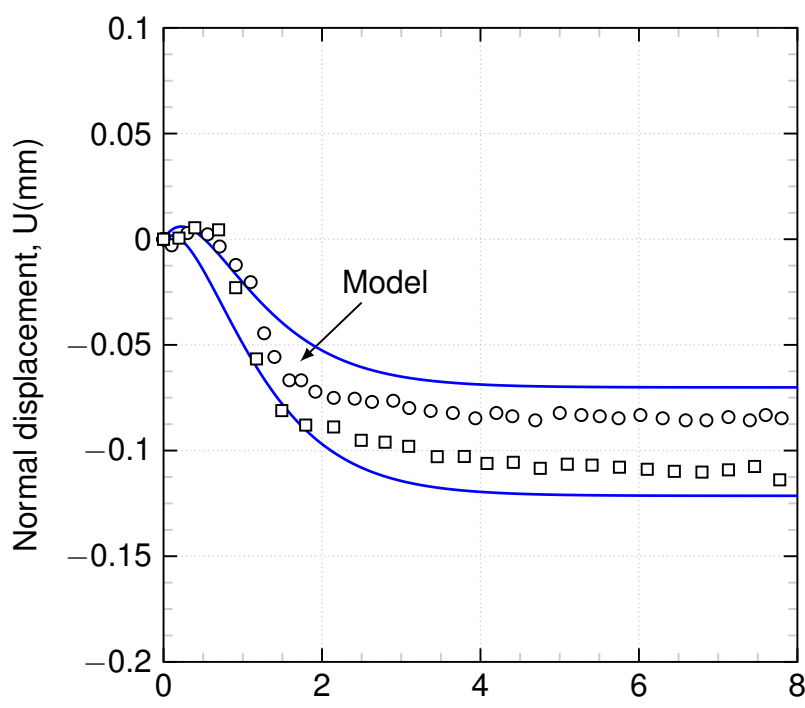

(b) Shear displacement, $\mathrm{W}(\mathrm{mm})$

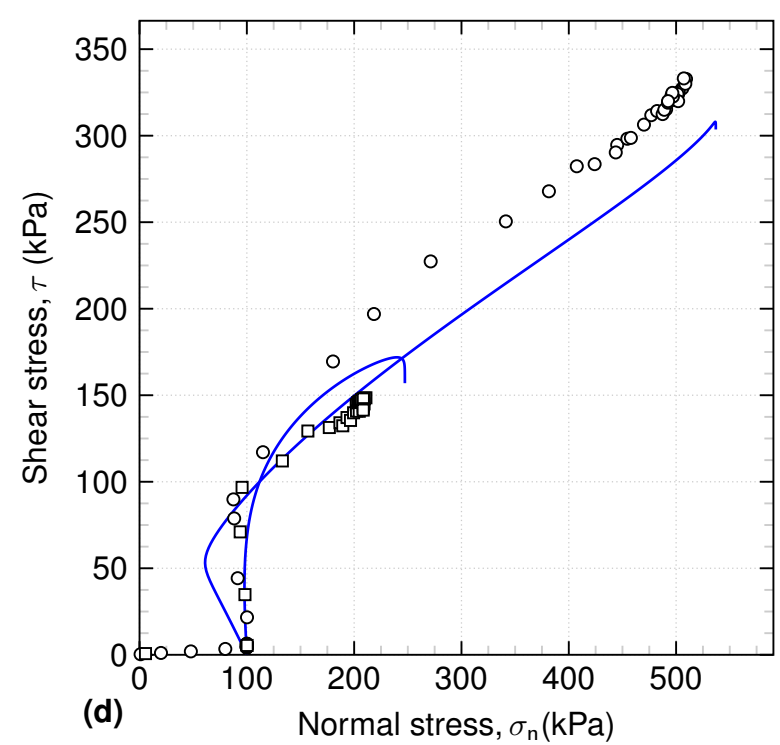

Fig. 8: Model performance against $C N S\left(\sigma_{n 0}=100 \mathrm{kPa}, \mathrm{K}=1000,5000 \mathrm{kPa} / \mathrm{mm}\right)$ Fontainebleau sand-structure interface test results under $100 \mathrm{kPa}$ of normal stress at $22^{\circ} \mathrm{C}$. (a) shear stress vs. shear displacement; and (b) normal displacement vs. shear displacement (experimental data by Maghsoodi et al. (2020b)). 

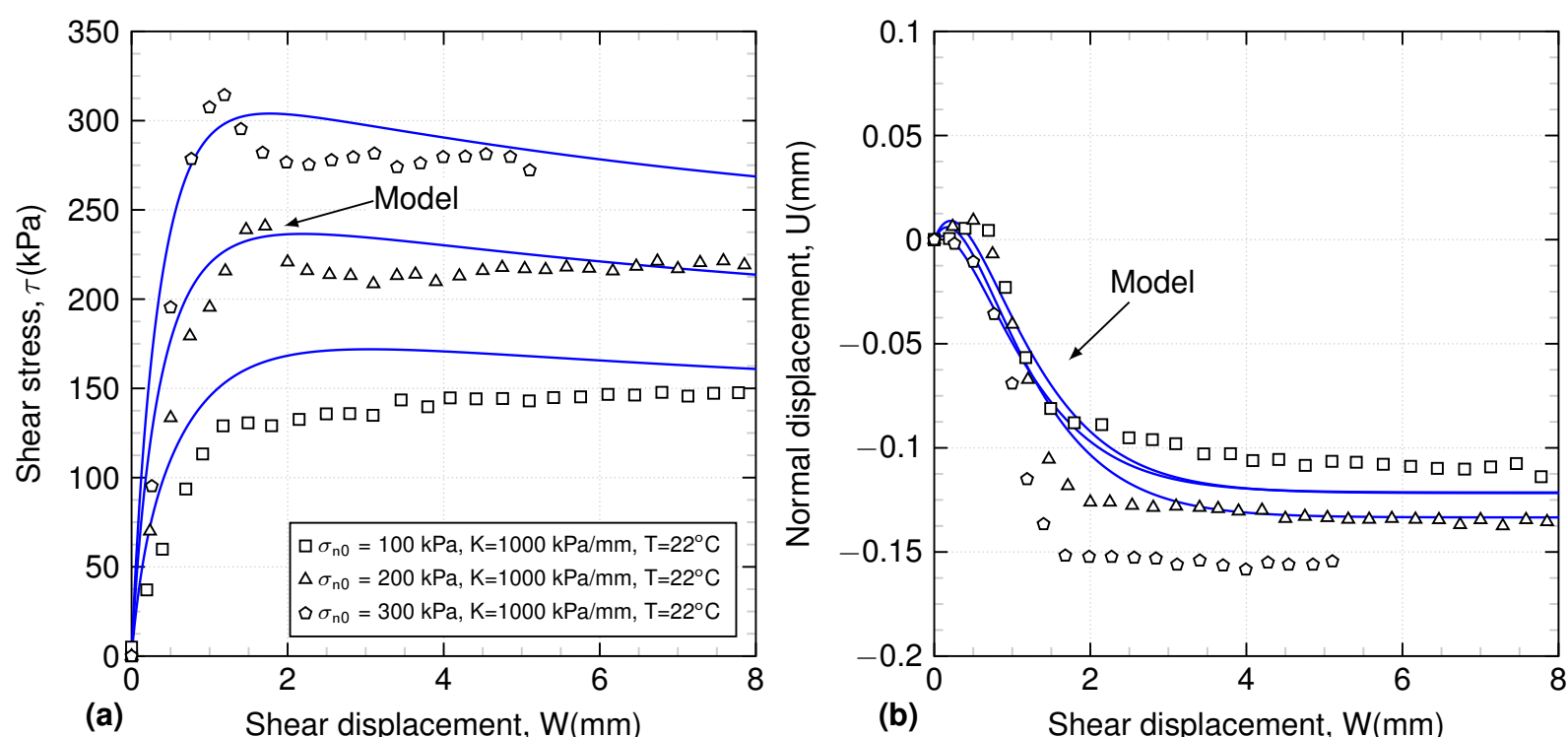

(a) Shear displacement, $\mathrm{W}(\mathrm{mm})$
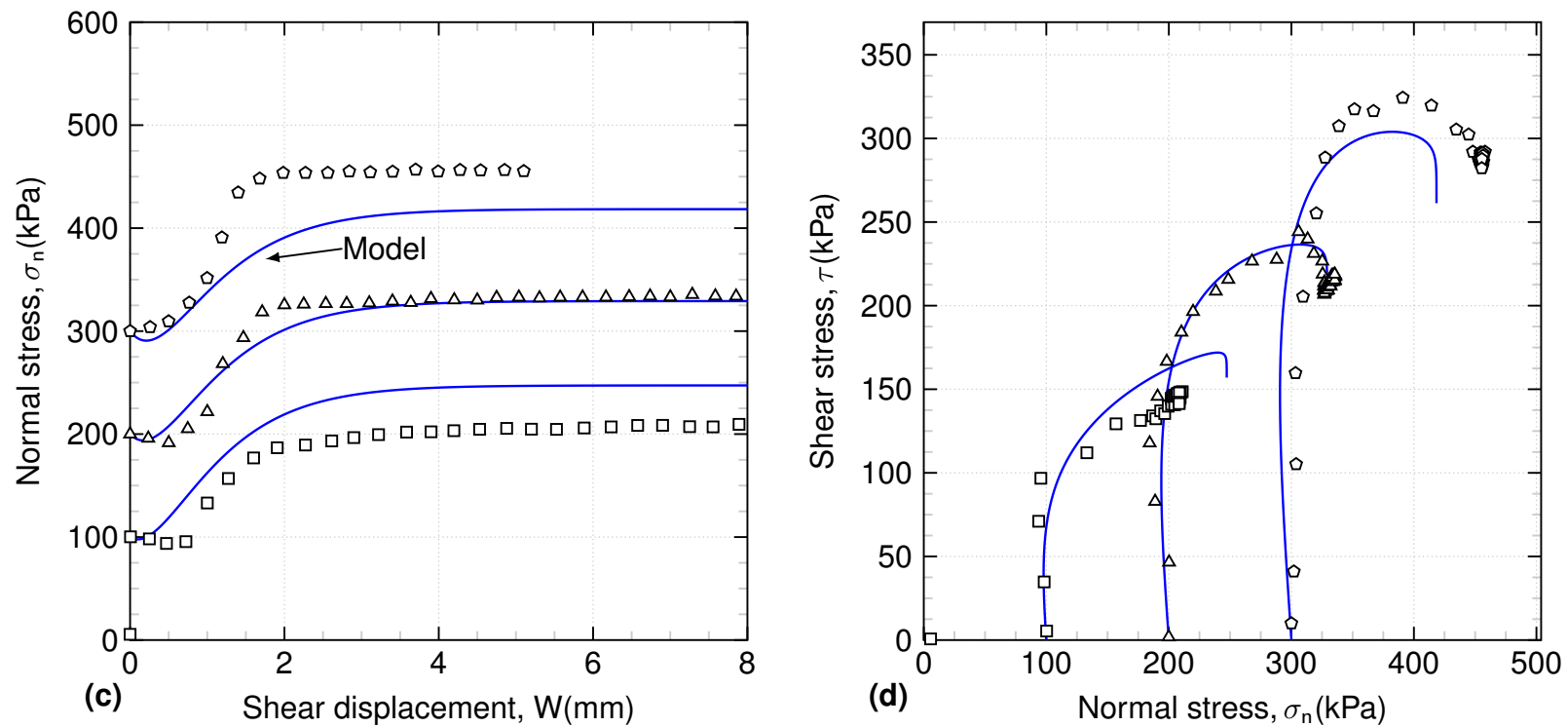

Fig. 9: Model performance against CNS ( $\left.\sigma_{n 0}=100,200,300 \mathrm{kPa}, \mathrm{K}=1000 \mathrm{kPa} / \mathrm{mm}\right)$ Fontainebleau sand-structure interface test results under $100 \mathrm{kPa}$ of normal stress at $22^{\circ} \mathrm{C}$. (a) shear stress vs. shear displacement; and (b) normal displacement vs. shear displacement (experimental data by Maghsoodi et al. (2020b)). 


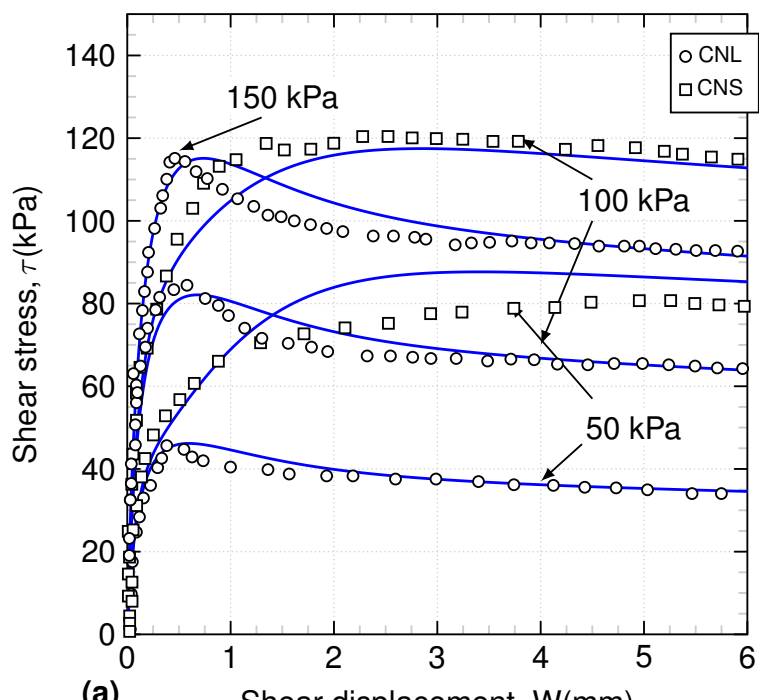

(a) Shear displacement, W(mm)

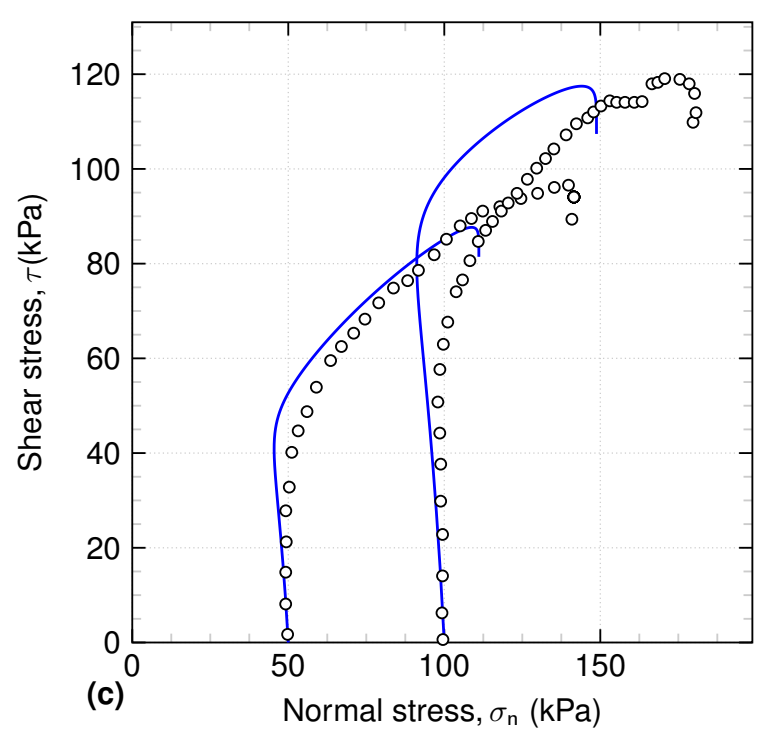

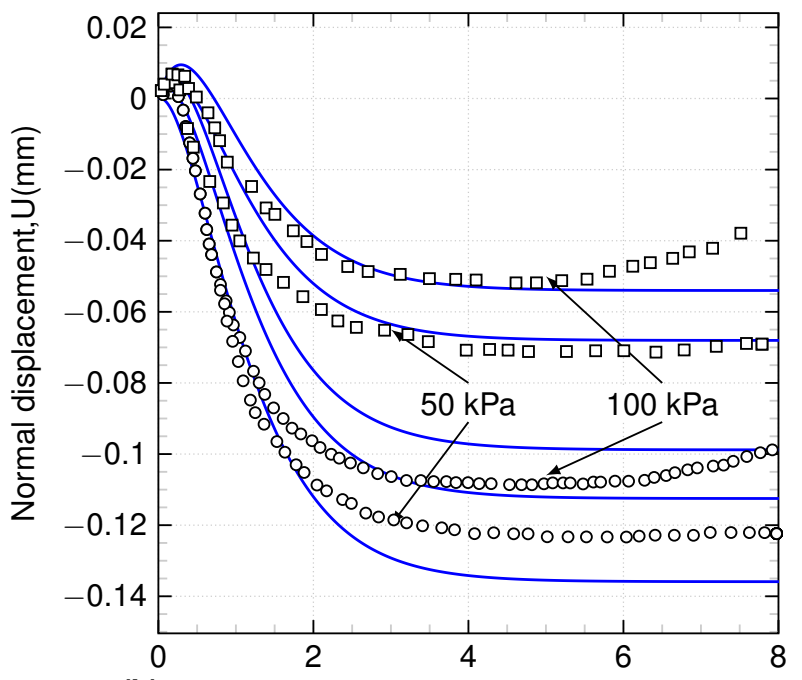

(b) Shear displacement, $\mathrm{W}(\mathrm{mm})$

Fig. 10: The interface model predictions against experimental data for $C N L\left(\sigma_{n}=50,100,150 \mathrm{kPa}\right)$ and $C N S$ tests $(K=$ $1000 \mathrm{kPa} / \mathrm{mm}$ ) on quartz sand-concrete interface: (a) shear stress vs. shear displacement; and (b) normal displacement vs. shear displacement; (c) normal stress vs. shear displacement (experimental data by Di Donna et al. (2015)) 


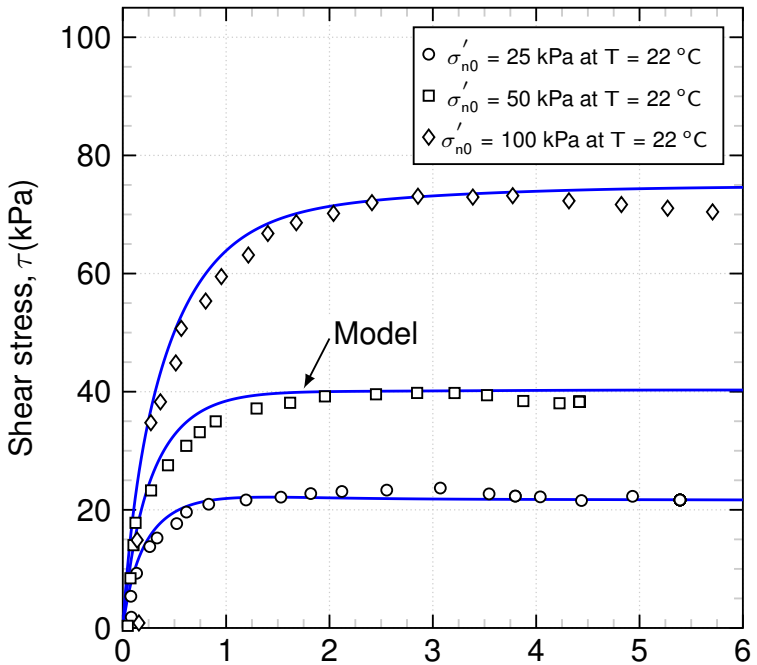

(a)

Shear displacement, $\mathrm{W}(\mathrm{mm})$

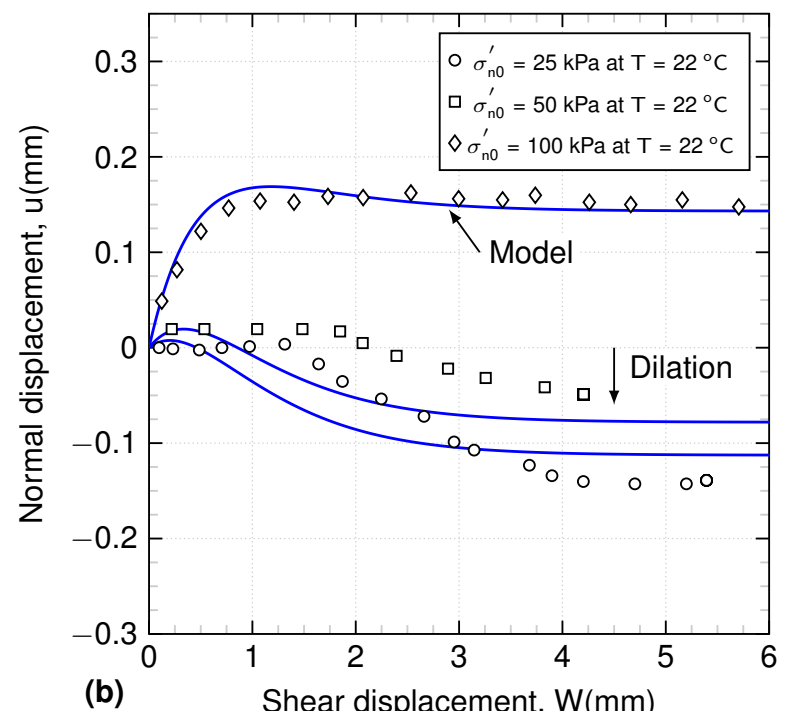

Fig. 11: The interface model predictions against experimental data for four constant normal stress tests (K $=0$ ) on interfaces between Fontainebleau sand and steel: (a) shear stress vs. shear displacement; and (b) normal displacement vs. shear displacement (experimental data by De Gennaro and Frank (2002)). 


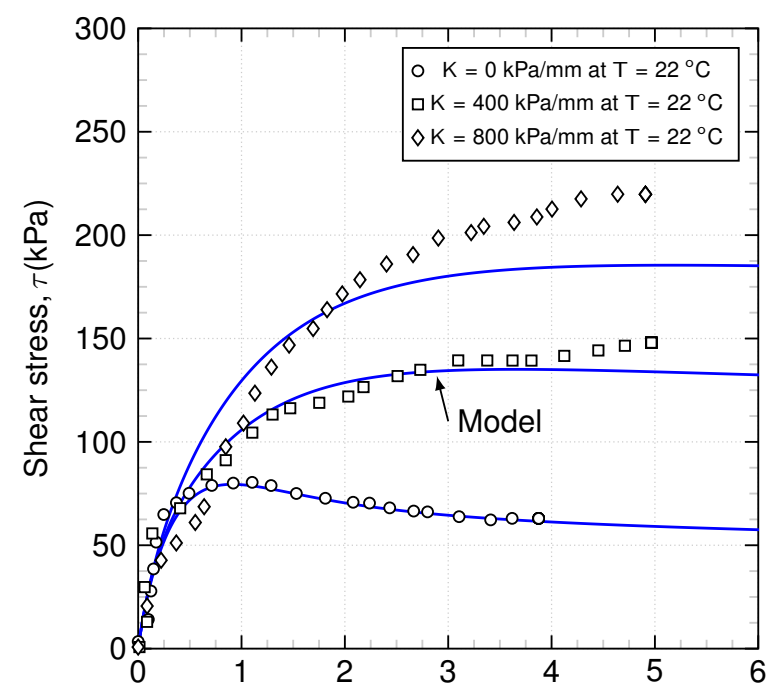

(a) Shear displacement, $\mathrm{W}(\mathrm{mm})$

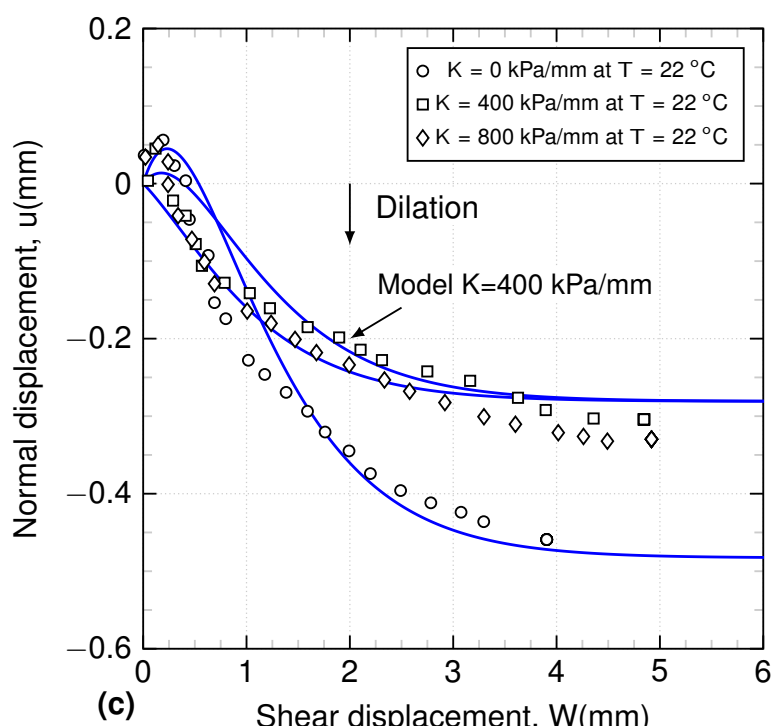

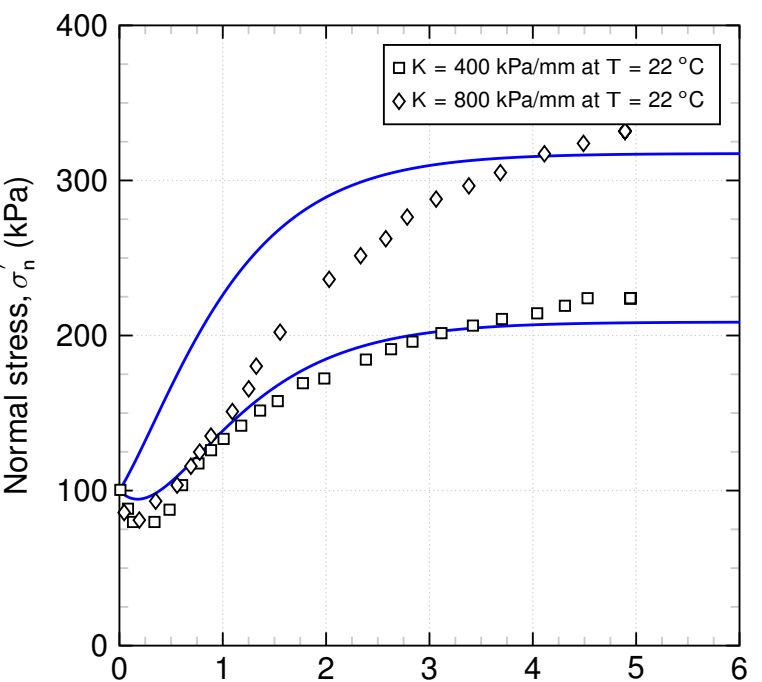

(b) Shear displacement, $\mathrm{W}(\mathrm{mm})$

Fig. 12: The interface model predictions against experimental data for four constant normal stress tests (K $=0$ ) on interfaces between Fontainebleau sand and steel: (a) shear stress vs. shear displacement; and (b) normal displacement vs. shear displacement (experimental data by Fakharian and Evgin (2000)). 

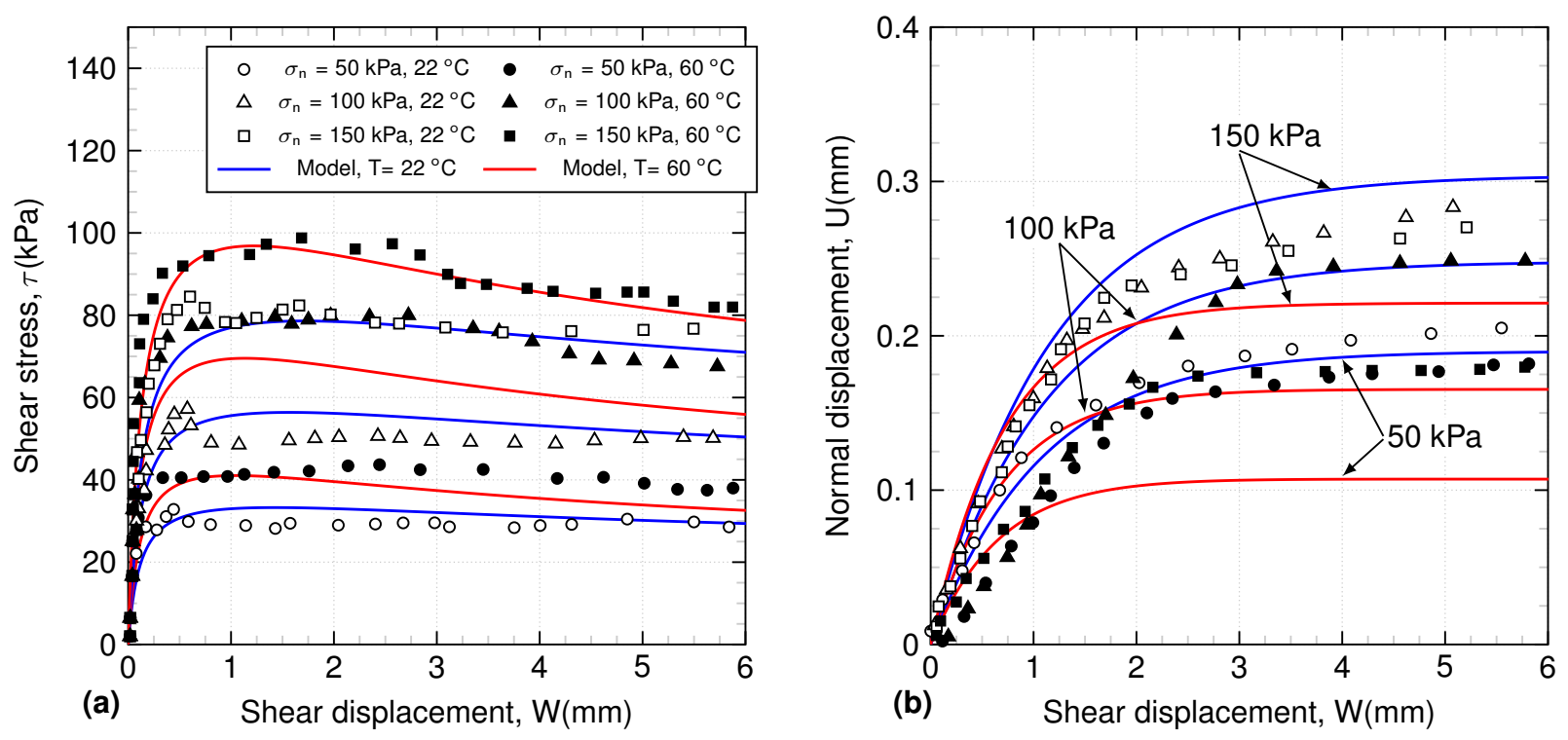

Fig. 13: The interface model predictions against experimental data for four constant normal stress tests (K $=0$ ) on interfaces between illite clay and concrete: (a) shear stress vs. shear displacement; and (b) normal displacement vs. shear displacement (experimental data by Di Donna et al. (2015)). 

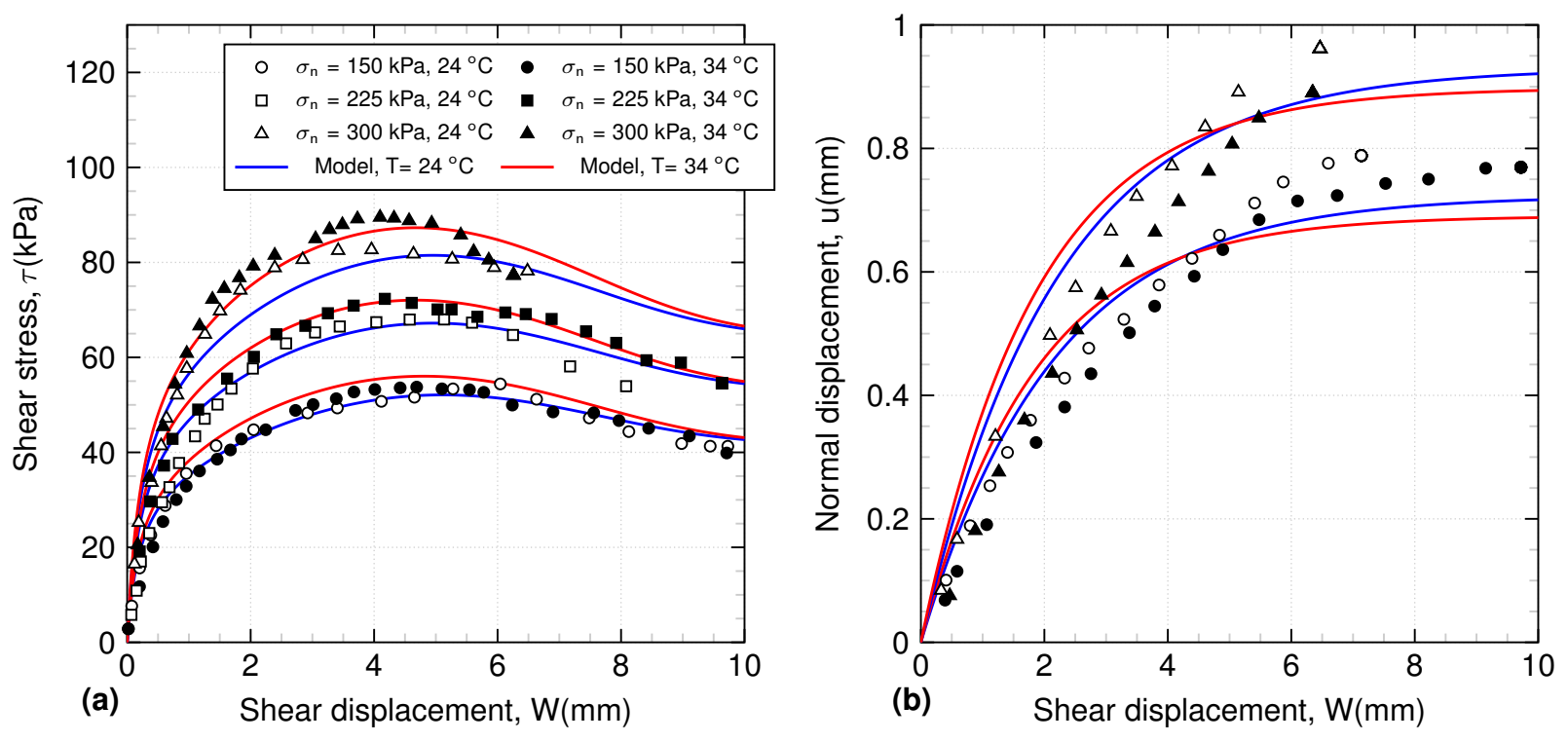

Fig. 14: The interface model predictions against experimental data for four constant normal stress tests $(K=0)$ on interfaces between illite clay and concrete: (a) shear stress vs. shear displacement; and (b) normal displacement vs. shear displacement (experimental data by Yazdani et al. (2019)). 

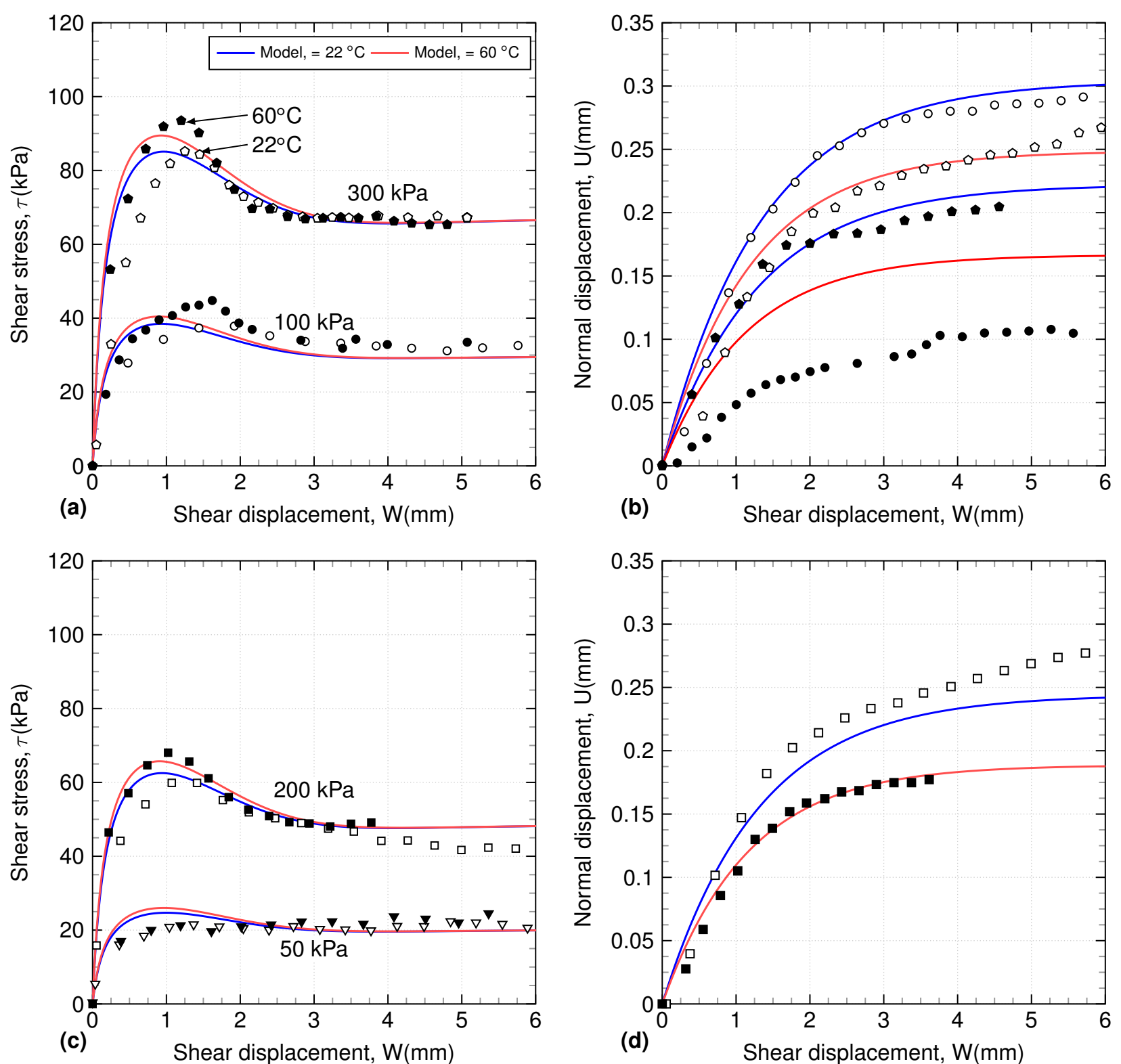

Fig. 15: The interface model predictions against experimental data for four constant normal stress tests (K $=0)$ on interfaces between kaolin clay and steel: (a)(c) shear stress vs. shear displacement; and (b)(d) normal displacement vs. shear displacement (experimental data by Maghsoodi et al. (2020b)). 


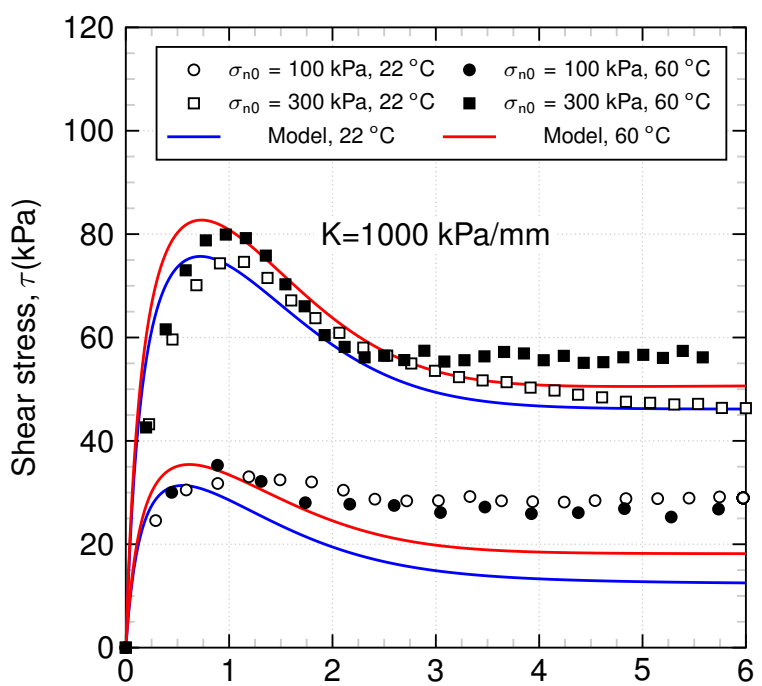

(a) Shear displacement, $\mathrm{W}(\mathrm{mm})$
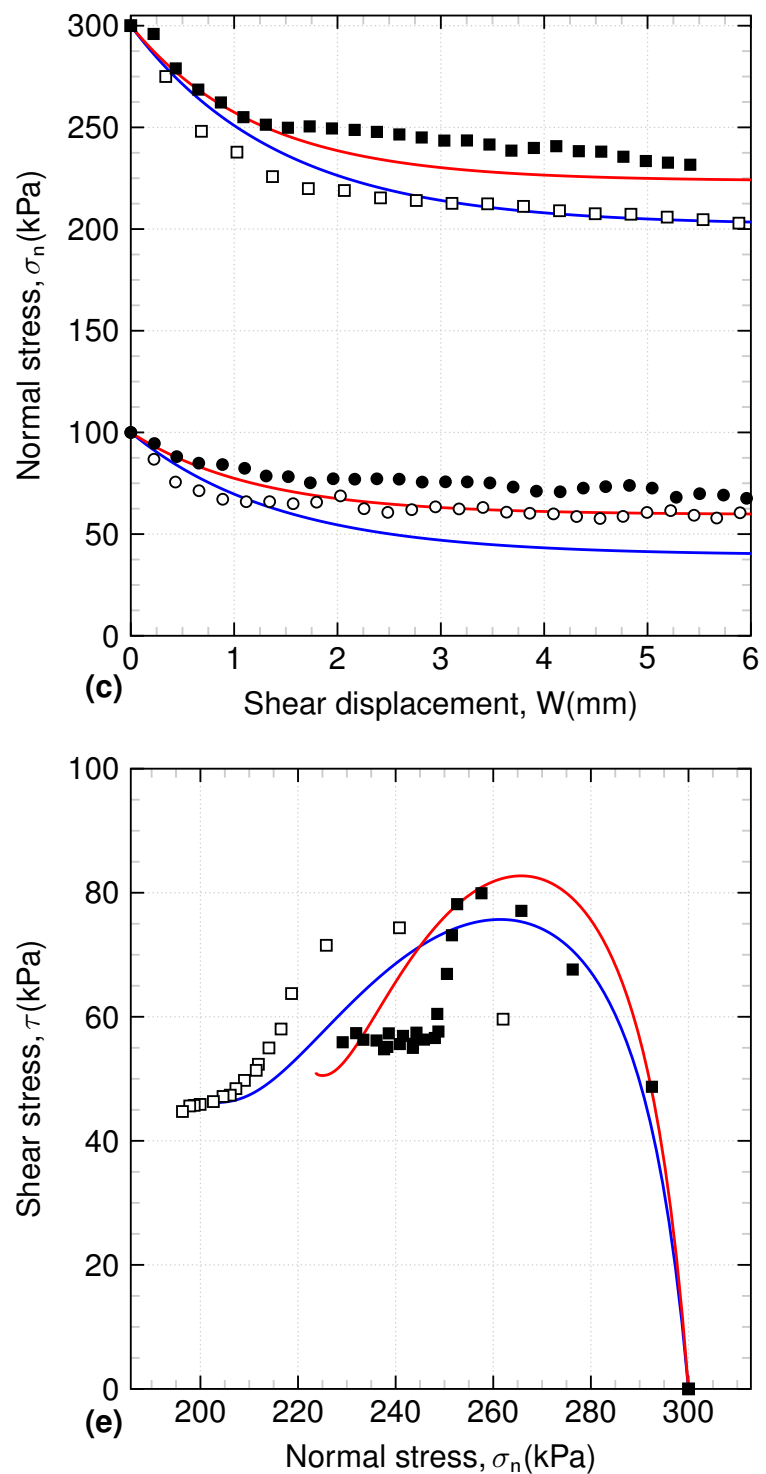

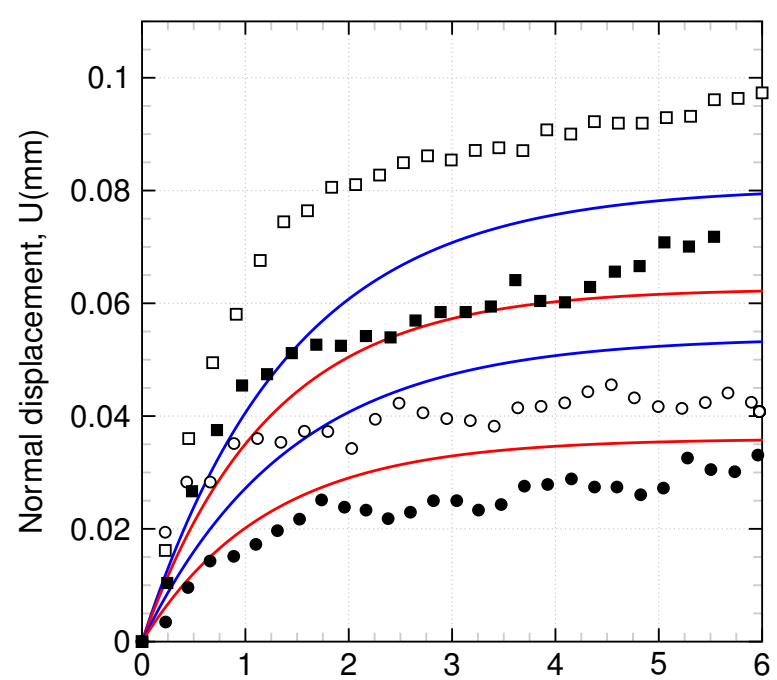

(b) Shear displacement, $\mathrm{W}(\mathrm{mm})$

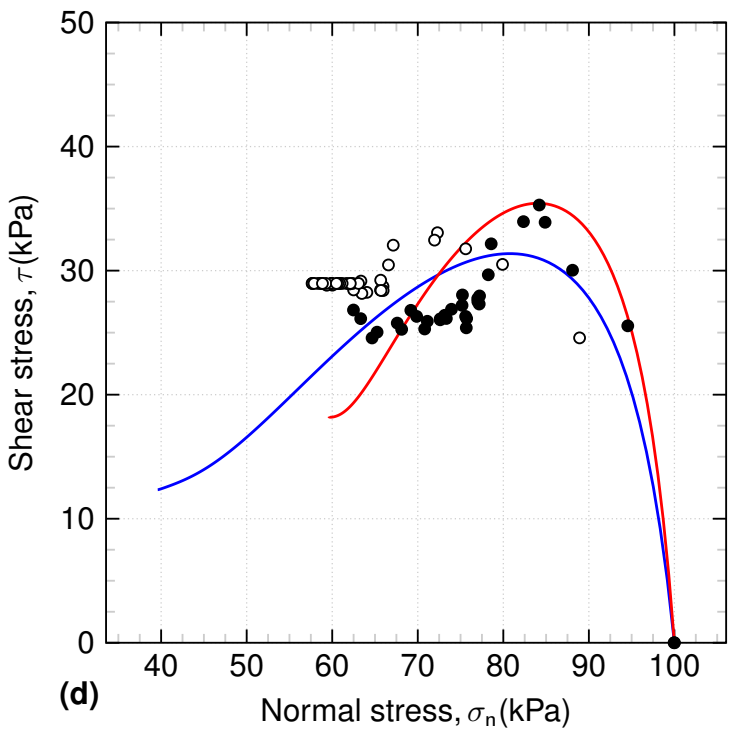

Fig. 16: The interface model predictions against experimental data for four constant normal stiffness tests $(K=1000$ $\mathrm{kPa} / \mathrm{mm}$ ) on interfaces between kaolin clay and steel: (a) shear stress vs. shear displacement; and (b) normal displacement vs. shear displacement (experimental data by Maghsoodi et al. (2020b)) 